\title{
MECHANICAL CHARACTERISATION OF TEXTILE CERAMIC PLATES. TESTING ON ELASTIC FOUNDATIONS
}

\author{
Ernest Bernat ${ }^{a^{*}}$, Lluis Gil ${ }^{a}$, Pere Roca ${ }^{b}$, Vicenç Sarrablo ${ }^{c}$ and Francesc Puigvert ${ }^{a}$ \\ ${ }^{a}$ Department of Strength of Materials and Engineering Structures \\ Technical University of Catalonia UPC. BarcelonaTech. \\ ETSEIAT, Colom 11. 08222 Terrassa, Spain \\ ${ }^{\mathrm{b}}$ Department of Construction Engineering \\ Technical University of Catalonia UPC. BarcelonaTech. \\ ETSECCPB. Jordi Girona 1-3. 08034 Barcelona, Spain \\ c Department of Architecture \\ International University of Catalonia. \\ ESARQ, Immaculada 22. 08017 Barcelona, Spain
}

\begin{abstract}
Textile Ceramic Technology (TCT) is a new material composed of ceramic units installed in a grid of steel wires. TCT application as a permeable pavement is expected to be a sustainable and aesthetic solution. In order to use TCT as a pavement, experimental research about the mechanical response of TCT placed on elastic foundations is required. The main aim of this paper is to provide the results of this experimental research. Different TCT types were tested in quasi-static and cyclic conditions. The paper presents also a numerical study and a real site application carried out to further evaluate the technology. Experimental, numerical and application results pointed out that TCT is sufficiently competent, from a mechanical point of view, to be used as a pavement for pedestrian and light traffic.
\end{abstract}

\section{KEYWORDS}

Technological pavement, textile ceramic technology, coefficient of ballast, cyclic test, numerical analysis

\footnotetext{
* Corresponding author:
}

Tel.: +34 937398728; fax: 937398994

e-mail address: ernest.bernat@upc.edu 


\section{INTRODUCTION}

The Textile Ceramic Technology (TCT) is an innovative material for building and civil engineering construction applications. It consists of an industrialized solution composed of high strength steel wires and ceramic units specially designed for this application. TCT consists of a mesh of steel wires, which are woven forming a grid, and ceramic bricks inserted within the voids of the grid. The system has been developed by a research group at Escola Tècnica Superior d'Arquitectura of Universitat Internacional de Catalunya (ESARQ-UIC) and has been patented [1]. Figure 1 shows a view of a typical TCT panel. TCT elements can be folded or rolled, transported easily and cast-in-place with additional mortar filling the gaps between units.

TCT was originally developed for building structural reinforced masonry shells following the works of Eladio Dieste in Uruguay, Argentina and Brazil. In fact, the first applications envisaged for TCT was the construction of reinforced masonry vaults, see Figure 2. Filling TCT joints with competent mortar allowed analysing the structural response of TCT as a case of reinforced masonry. This approach was presented in $[2,3]$.

The material offers interesting architectural and structural possibilities and can be used to cover large surfaces with satisfactory structural performance, appealing aesthetics and easy execution.

Research on general solutions for reinforced masonry shells and walls has been already carried out by different authors. The study of reinforced brickwork walls under out-of-plane loads, has been analysed in [4] and the blasting effects have been researched in [5]. The behaviour of reinforced masonry has already been described by means of analytical approaches [6], and finite element analyses $[7,8]$. However, and according with the literature consulted by the authors, steel reinforced masonry has not yet been studied as a flexible and permeable pavement material.

Performance of structures does not only depend on the strength of the materials used but also on the shape of the structure, the boundary conditions or its loading patterns. Thus, it is expected that TCT behaves differently when used for different applications such as façades (see [9]), pavements, floors, roofs, etc. The first studied industrialised use of TCT was as a pavement because it permits the exploitation of most of the TCT advantageous properties. TCT pavement application stands out for its flexibility, speed and little cost at covering huge areas. 
Industrialised application, permeability and mechanical flexibility are the main characteristics of the TCT used as a pavement. Large work has been done on the mechanical study of flexible pavements $([10,11])$ and also on the research about the permeability $([12-14])$. In contrast, only a few researches have been found on the industrialisation process of the pavement execution. Furthermore, the past studies have reported construction procedures very different to the presented herein. For example, [15] is based on an intensive use of robotics.

The main objective of this research has been studying the mechanical performance of TCT used as a pavement for light traffic. For that purpose, the performance of TCT sheets on a deformable substratum (similar to a foundation soil) has been analysed in laboratory conditions. The work follows an experimental approach involving the test of TCT layers under static and cyclic loads representing light urban traffic including pedestrian and light vehicle one. The application of TCT as a pavement for heavy traffic would require further investigation. It has to be remarked that the first aim of this study is to present the testing procedures and the obtained mechanical response of this new material, TCT. Nevertheless, Finite Element Analysis has been used to accurately determine the stress distribution in the contact between the TCT and the elastic basis. This has allowed calculating the ballast coefficient of the TCT plate by using an analytical approach herein presented.

\section{MATERIALS AND METHODS}

In this section the test samples and the testing procedure are described. Although the full experimental campaign carried out also comprised tests on the mechanical characterization of the TCT components, the present paper focuses on the specific application to pavements laid on elastic substratum.

Four different types of TCT plates were tested depending on the sort of ceramic units utilized (hollow bricks or solid tiles) and the nature of the joint filling material (mortar, sand or empty joints). All tests were carried out over an elastic base to represent the deformability of the soil in a simplified way.

Two different test setups were used depending on the type of ceramic pieces included in the sample. For each test setup, two different kinds of tests were carried out, namely a quasi-static tests to study the behaviour of TCT under a compressive load and a low frequency cyclic test to assess the performance of this new material when used as a pavement for traffic consisting of light vehicles. 


\subsection{Elastic foundation}

The behaviour of a TCT plate supported on soil might be experimentally modelled by laying the ceramic membrane on an artificial elastic medium. Following this approach, an elastomeric sleeper pad made of rubber was used to model a soil in the laboratory tests. The elastic properties of the elastomeric pad were selected to meet the deformability of a typical sand or compacted clay soil. Thus, a sleeper pad with a coefficient of ballast $(K)$ between $0.05 \mathrm{~N} / \mathrm{mm}^{3}$ and $0.09 \mathrm{~N} / \mathrm{mm}^{3}$ (corresponding with a CBR -California Bearing Ratio- between 10\% and 25\%) was selected for the experimental campaign.

The value of the coefficient of ballast of the used elastomeric sleeper pad, consisting of a piece of one square metre of Slitrack ${ }^{\circledR}$ M20 AVC700, 20mm thickness, was experimentally determined in quasistatic and cyclic conditions. Figure 3 shows the behaviour of the elastomeric sleeper pad in the quasistatic loading test (with the same procedure as presented in section 2.3.1). An experimental static coefficient of ballast of $0.0631 \mathrm{~N} / \mathrm{mm}^{3}$, corresponding to a CBR of approximately $12.5 \%$ or to a compacted sand-clay soil, was obtained. The first and last loading cycles of the cyclic test on the elastomeric sleeper pad are represented in Figure 4. According to these preliminary experiments, the cyclic coefficient of ballast, which is different from the static one, did not change during the cyclic test (in contrast with the maximum and minimum loads associated to the fixed displacement limits of the cyclic test, see section 3.2). This fact has to be taken into account since the most common soils usually show an increasing cyclic coefficient of ballast when cyclic loads are continuously applied. Thus, the used rubber sleeper has properties which are more constant than the current soil. This situation is intended to help at analysing the obtained results, which are focused on characterising the TCT response. A value of $0.1419 \mathrm{~N} / \mathrm{mm}^{3}$ was obtained for the cyclic coefficient of ballast. These properties (static and cyclic coefficient of ballast) of the sleeper pad are useful in the interpretation of the results to distinguishing between the deformation of the elastic support and that of the TCT.

\subsection{TCT Plates}

Four different types of TCT were tested depending on the type of the ceramic units and the material used to fill the joints. In total, six specimens were fabricated to be tested and twelve tests were carried out. Table 1 summarises the geometric characteristics and the weight of the tested samples. The length, $L$ and width, $W$ were measured with a precision of $1 \mathrm{~mm}$ whereas the thickness of the 
joints were measured with a precision of $0.01 \mathrm{~mm}$. The mass was determined with an electronic scale with $5 \mathrm{~g}$ precision. This table shows tests carried out with each specimen. TCT plates of hollow bricks were formed by 9 rows of 4 pieces each whilst TCT plates of solid tiles were made by 9 rows of 5 pieces each. The dimensions of the hollow bricks dimensions were $235.5 \times 95.2 \times 44.1 \mathrm{~mm}^{3}$ and those of the solid ceramic pavement stones (tiles) were $200.0 \times 98.6 \times 50.8 \mathrm{~mm}^{3}$.

In each joint between columns three wires were placed but only two wires were embedded in the joints between rows. These were zinc-coated steel wires with a diameter of $1.80 \mathrm{~mm}$. The properties of the component materials are summarised in Table 2. These are experimentally obtained in all cases. Common construction sand with a maximum aggregated size of $2 \mathrm{~mm}$ was used to fill the joints of the SS and CS specimens (as defined in Table 1).

The mortar joints were executed in the production place of TCT system and air-cured for 28 days before the test. On the contrary, the sand was placed in-situ after positioning the TCT membrane in the test set up for the specimens with sand-filled joints. A generic view of specimens is shown in Figure 5. Figure 6 shows a sketch of the tested TCT systems corresponding with the two different ceramic pieces and Figure 7 shows a sketch of a generic TCT element.

\subsection{Methods}

Seven tests were carried out on TCT specimens formed by hollow ceramic bricks and five tests corresponded with samples made with solid pavement ceramic tiles. The test setup was the same for both types of specimens except for the position of the sensors, which is shown in Figure 6 . The test configuration was also the same for both static and cyclic tests. The testing procedure comprised the following tasks: a) measuring the main characteristics of the samples and inspecting for possible damage; b) positioning the sample over the elastomeric sleeper pad; b1) (when needed) filling the TCT joints with sand for samples B01 and P01; c) placing the sensors in the corresponding position; d) adjusting the loading tool (steel plate of $150 \mathrm{~mm} \times 150 \mathrm{~mm}$ ) and moving it to the initial contact with the sample.

The loading tool was $150 \times 150 \mathrm{~mm}^{2}$ to represent a tire stamp corresponding to commonly used light maintenance vehicles. Most of these vehicles use 155 or 165 mm width tires (e.g. 155/80 R13 or $165 / 65$ R14 models) and the maximum weight of some of them might overpass $20 \mathrm{kN}$. Because of this, a representative value of the maximum load of one wheel of these vehicles is set to $6 \mathrm{kN}$ to perform a 
conservative analysis of the application of TCT as a pavement.

The sensors consisted of 4 displacement potentiometers $(0.01 \mathrm{~mm}$ precision) to measure the deflection of the TCT plate in 4 centred symmetric points at approximately one third of the sample side length, 2 displacement potentiometers to measure the displacement of the loading tool and 4 lasers $(0.4 \mathrm{~mm}$ precision) to double the measures of the first 4 potentiometers in case their glued attachment with the TCT plate failed during the cyclic tests. All these sensors were held by an external structure which was not in contact with neither the loading nor the support system.

The load application system was aimed to distribute the load on the TCT plate. Thus, it was placed so as to contact with the maximum number of ceramic pieces. The edges of the steel plate were kept at $45^{\circ}$ from the joint directions (see Figure 6). The load was applied with a dynamic hydraulic actuator of $50 \mathrm{kN}$ and all data were simultaneously acquired and recorded at $50 \mathrm{~Hz}$.

The specific aspects of the static and cyclic tests are presented in the next subsections.

\subsubsection{Static load test}

The load was applied at $500 \mathrm{~N} / \mathrm{min}$ up to $6 \mathrm{kN}$. After that, this load was maintained constant for 1 minute to measure any possible viscoelastic deformation before unloading at $2 \mathrm{kN} / \mathrm{min}$. Only the loading data was used for later on analysis so the unloading process was carried out faster than the loading one. The graphical representation of the loading procedure for static tests is shown in Figure 8.

\subsubsection{Cyclic load test}

It was decided to apply the cyclic load by displacement control because of its better accuracy in the test execution. For this reason, a previous short-term test thought to calibrate the cyclic test parameters was needed for each specimen. It consisted of adjusting the displacement range that corresponded with the load range comprised between $2 \mathrm{kN}$ and $5 \mathrm{kN}$ when the load was applied following a sinusoidal shape at $2 \mathrm{~Hz}$. Then the following loading procedure was executed: a) applying an increasing compressive load at $2 \mathrm{kN} / \mathrm{min}$ up to $3,5 \mathrm{kN}$; b) maintaining this load constant for 1 minute; c) applying the cyclic load ranging from $2 \mathrm{kN}$ to $5 \mathrm{kN}$ at $2 \mathrm{~Hz}$ for 1000 cycles; d) unloading at $2 \mathrm{kN} / \mathrm{min}$. Only the data corresponding to the cyclic loading of these tests was taken into account. The graphical representation of loading procedure for cyclic tests is shown in Figure 8. 


\subsubsection{Determination of the static and dynamic coefficient of ballast of TCT plates}

Static and cyclic coefficients of ballast corresponding to different typologies of TCT plates were determined from the experimentally acquired data. The stress distribution over the thickness of the TCT plates or in the elastic basis has not been addressed because the main aim of this research was to analyse the apparent deformation of the TCT system when it was used as a pavement on an elastic basis. However, the influence of the contact area between the TCT and the basis has been considered as an essential parameter to address a simplified calculation of an equivalent coefficient of ballast for the TCT elements which might be useful for direct practical applications. A sketch of the stress transmitting areas and the corresponding deformations is presented in Figure 9.

In order to interpret the experimental results, it is important to take into account that the load was applied on the TCT with a steel plate (loading tool). The contact area between the loading tool and the TCT was $A_{0}=150 \times 150 \mathrm{~mm}^{2}$. In addition, the following hypotheses were considered to carry out this analysis:

- The load transmission area of the TCT on the elastomeric base, $A_{1}$, depends on the type of TCT plate studied. Each TCT configuration is supposed to behave differently so that the load would be transmitted downwards also in a different way. The later on presented simulations (section 4) have been used to accurately obtain these transmission areas, $A_{1}$. In Figure 10 and Table 3 the loaded area of the elastomeric base for each case is shown.

- Although the stress distribution in the TCT-base contact predicted by the numerical model (see section 4) was approximately conical (triangular and axisymmetric) and the experimental evidences (see section 3) show that the stress distribution was not uniform, an equivalent uniform stress distribution is assumed to calculate the coefficients of ballasts. The uniform stress is set so the resultant force was equal to the applied one. This assumption is based on the fact the coefficient of ballast should be obtained by measuring a uniformly applied load and the corresponding uniform descending movement of the soil. In addition, the descending movement applied with the loading tool in the tests was uniform and the corresponding normal stress on the upper TCT surface was also mostly uniform (only some border effects were predicted by the numerical model presented in section 4).

- Elastomeric base (sleeper pad) and TCT plates behave elastically. Thus, the total measured 
deformation $(\delta)$ is the addition of the deformation in each material (TCT, $\delta_{0}$, and base, $\left.\delta_{1}\right)$. See Figure 9 for a representative sketch of these deformations.

To calculate the static coefficient of ballast of TCT plates from the tests results the following procedure was followed:

- Firstly, the deformation of the sleeper pad $\left(\delta_{1}\right)$ was obtained as

$$
\delta_{1}=\frac{N_{/ A_{1}}}{K_{1}}=\frac{6000}{0.0631 \cdot A_{1}}
$$

Knowing the applied load $(N=6000 N)$, the static coefficient of ballast of the elastic base $\left(K_{1}\right)$ and the loading area for the elastomeric support $\left(A_{1}\right)$ which is represented in Figure 10 and summarised in Table 3.

- Secondly, the deflection of the TCT was calculated $\left(\delta_{0}\right)$ as the difference between the average total deformation measured $(\delta)$, and that of the elastomeric base, according to

$$
\delta_{0}=\delta-\delta_{1}
$$

- Thirdly, the static coefficient of ballast of the TCT plate $\left(K_{0}\right)$ is calculated from the value of its deformation $\left(\delta_{0}\right)$, the applied load $(N=6000 N)$ and the load application area $\left(A_{0}\right)$ using the following equation (Eq. 3):

$$
K_{0}=\frac{N / A_{0}}{\delta_{0}}=\frac{6000}{\delta_{0}^{-150-150}}
$$

To calculate the cyclic coefficient of ballast of TCT plates $\left(K_{\text {dyn_o }}\right)$ from the results of the cyclic tests, the following equation was utilized (Eq. 4):

$$
K_{\text {dyn_0 }}=\frac{N / A_{0}}{\delta_{0}}=\frac{1}{150-150 \cdot\left(\frac{1}{N_{b_{6}}-\frac{1}{A_{1}-K_{d y n_{-}}}}\right)}
$$

where $(N / \delta)$ is the total force-displacement relationship of the whole tested system for a representative cycle, $\left(K_{d y n} \_\right)$is the cyclic coefficient of ballast of the sleeper pad $\left(0.1419 \mathrm{~N} / \mathrm{mm}^{3}\right.$ as presented in section 2.1) and $A_{1}$ is the stress transmitting area on the elastomeric support (see Table 
3).

\section{EXPERIMENTAL RESULTS}

Sections 3.1 and 3.2 present the static and the cyclic test results respectively. In both cases, the two main parameters for the post-processing of the acquired data are the applied load and the measured deflection in the loading area. Also in both cases, the final result is found in the calculation of the coefficient of ballasts (static and cyclic) of each kind of TCT plate.

\subsection{Static load test}

Table 4 presents the initial and final out-of-plane deformation of the loading plate when $6 \mathrm{kN}$ were constantly applied for a minute. The standard deviations presented in brackets in this table are referred to the two external measurements made with the potentiometric sensors attached to the loading tool. It has to be remarked that these statistics parameters are more related with the slightly unlevelled descending displacement of the loading steel plate, due to the samples' surface irregularities, than with the accuracy of the measurement. In fact this deviation is maintained during the time with constant load applied for most of the cases, so both sensors measured the same displacement due to the viscoelastic response although they had different starting points (initial deformation). Under the constant load the system exhibits viscoelastic behaviour attributed to the elastomeric pad. This effect was recognisable in the measured data ( $d$ in Figure 3 ). In absolute values, the sleeper pad gained a deformation of $0.08 \mathrm{~mm}$ during the period of constant load. Similarly, the viscoelastic deformation at the end of the test of the complete system (TCT + elastic base) was $0.07 \mathrm{~mm}$ for BM1_SM test. However, this particular test showed a large increase of the deviation of the measurements of the out-of-plane deformation. This means that one of the potentiometers moved significantly more than the other one, which might suggest that the data acquisition could not be as accurate as for the other cases. In fact, it is worth mentioning that the average of the viscoelastic deformation for the complete system tests (TCT on the elastomeric base), no taking into account BM1_SM case, was 1.6\%. This value might be littler than the corresponding to the elastic base $(1.8 \%)$ due to increasing the loading area of the sleeper pad. The TCT distributes the load and the stress received by the sleeper pad is less than for the static test on the elastic base. Thus, the viscoelastic deformation of the TCT+ base system seems to be mostly due to the elastic base. 
The values of the out-of-plane total displacements presented in the second column of Table 4 (just after reaching $6 \mathrm{kN}$ load) were used to calculate the static coefficient of ballast of each type of TCT plate, $K_{0}$, according to section 2.3.3. These results are summarised in Table 3. For the B0 case an average value of the tests B01_SE and B01_SS has been considered for calculation.

The static test response for TCT samples composed of hollow bricks is shown in Figure 11. As expected, the behaviour clearly changes depending on the joint type. Those with empty or sand-filled joints (B0) presented higher deformations than the sample with mortar cast joints (BM). It is also worth noticing that the deformation of the sand-filled samples and empty joints specimens are approximately the same: $2.48 \mathrm{~mm}$ for the empty and $2.34 \mathrm{~mm}$ for the sand-filled which turned to $2.52 \mathrm{~mm}$ and $2.37 \mathrm{~mm}$ respectively after one minute of constant load. For this reason, this distinction was not made in the following tests on the TCT plates composed by solid pavement ceramic pieces. Results of TCT plates with solid pieces are presented in Figure 12. The main difference by comparing these tests with the ones with hollow bricks is that the behaviour seems not to be dependent on the type of joints until 1.5kN. For greater loads, the TCT specimen with sand-filled joints (P01_SS) achieved greater values of deformation $(2.28 \mathrm{~mm})$ than the one with mortar joints (PM1_SM) which deformed $1.95 \mathrm{~mm}$. These results are numerically represented in Table 4.

It has to be noticed that the total out-of-plane deformation of the TCT systems (placed on elastomeric bases) is less than the deformation of the sleeper pad alone $(4.45 \mathrm{~mm}$ that grew to $4.53 \mathrm{~mm})$ due to the load distribution effect of the TCT. Thus, it has experimentally confirmed that the TCT distributes the load and it has been proved that the transmitting stress area on the elastic base, $A_{1}$, is larger than the initial force application surface $\left(A_{0}\right)$.

TCT response under static loading conditions was clearly different depending on the joint material. Behaviour of those plates with mortar joints (BM1 and PM1) was characterised by:

- The lifting of the plate corners (up to $5 \mathrm{~mm}$ ) when the plate was quasi-statically loaded on its centre. This happens because of the bonding qualities of the mortar, which connected the ceramic pieces, and due to the higher stiffness of the TCT plate if compared with the elastomeric base. In addition, this evidence indicates that not all the upper side of the sleeper pad was compressed. This fact supports the initial description of a triangular (or conical in 
three-dimensional analysis) stress distribution in the contact between the TCT and the sleeper pad. Moreover, this effect is also supported by the numerical results of the finite element analysis used to calculate the TCT-base contact area $\left(A_{1}\right)$. Thus, the hypothesis of a uniform stress distribution is a simplification of the real response only used to obtain an equivalent coefficient of ballast with practical applications at designing TCT pavements where equivalent properties are required. However, this hypothesis cannot be used to predict the stress distribution neither in the TCT nor in the elastic base according with the presented results.

- The asymmetric deformation. Qualitatively, it was observed that sensors placed in the same column systematically measured less deformation than the ones placed in a row. This proves the orthotropic response of TCT plates due to their geometric definition.

When there was no mortar in the joints (B01 and P01 specimens), none of the corners seemed to lift when applying load at the sample's central area and the four sensors placed approximately at thirds of the side length measured less deformation than in the cases with casted joints. In B01 and P01 cases the orthotropic effects, due to the geometric definition of the TCT, are less evident than in the cases with mortar joints. No difference was noticed between placing sand in the joints and leaving them empty.

\subsection{Cyclic load test}

Table 5 summarises the experimental results of the cyclic tests on TCT plates. The table includes the values of the load loss between the first and last loading cycles for each sample, showing a viscoelastic effect that caused a decrease in the load under the maintained deformation range. This effect was due to the fact that the cyclic loading procedure was carried out through displacement control as explained in section 2.3.2. Although the load decrease directly caused by the elastic base (6.5\%) might explain up to the $90 \%$ of the total system load decrease (averages $7.3 \%$ ), the remaining $10 \%$ could indicate a viscoelastic deformation effect of the TCT plates under cyclic solicitations that should be taken into account and might be related with the steel wires used in the TCT.

Load-deformation ratios for the first and last loading cycles were used to calculate the cyclic coefficient of ballast $\left(K_{d y n_{1}}\right)$ corresponding to each TCT type. This calculation was done according to the hypothesis presented in section 2.3.3. Results are shown in Table 3. Comparing them, a large difference is observed between the samples with mortar joints and those with sand-filled or empty 
joints in the case of hollow brick pieces. The tendency is the same as in static tests, with higher values of the coefficient of ballast for the samples with no mortar into the joints. Regarding the cyclic coefficient of ballast, there is not much difference between placing or not a mortar joint for the samples with solid tiles.

The cyclic response for each test is represented in Figures 13-15. The load-deformation ratio used in the calculation of the cyclic coefficient of ballast for each case is obtained from the corresponding plot as the slope between the extreme points of the cyclic curves.

The following aspects have been noticed on the TCT experimental response:

- In the specimens with mortar joints (BM1, BM2, PM1 and PM2), the vibration applied on the centre of the sample was strongly transmitted to the entire membrane and the corners experienced notable vibration. The range of vibration amplitude of the corners is estimated to be greater than $5 \mathrm{~mm}$. This response meets the results of the static tests and the numerical results on static cases that predicts a conical stress distribution in the TCT-base contact.

- If the joints are empty (B01_CE), the corners did not receive the vibration and no displacement was observed in these extreme positions.

- If the cases with sand-filled joints, the behaviour depended on the TCT type. For those with hollow ceramic bricks (B01_CS), sand losses were observed (see Figure 16), and the vibration was transmitted to the corners of the samples (ranging up to $2 \mathrm{~mm}$ ). In the specimens composed of solid ceramic pavement pieces (P01_CS), the sand level remained constant and no vibration was transmitted to the corners of the sample.

In all cases, a little loss of stiffness (decreasing of the dynamic coefficient of ballast) was observed.

\section{SIMULATIONS}

In this section, the numerical model used to simulate the structural response of the static tests is described. The main objective of using this tool is to accurately obtain the stress transmitting area, $A_{1}$, in the contact between the TCT and the elastic base, which has been used in section 3 to calculate the coefficients of ballast. As a secondary result, force vs. out-of-plane deformation response is obtained. For those purposes, a detailed model has been elaborated in which the ceramic units, the transverse 
and longitudinal steel bars are described individually using different partial material models. The response of mortar and ceramics in tension is described by means of a smeared cracking formulation in combination with a model for fragile materials including a post-peak softening branch. In compression, the response of both materials was described by means of the Drucker-Prager plasticity model. The steel response was modelled by means of a bilinear diagram with a yielding limit defined by the von Mises criterion in combination with additional branches for the modelling of the hardening due to unloading and reloading cycles. However, according with the results presented in this section, the different parameters needed for modelling TCT do not require the implemented non-linear failure description as the TCT behaves always linear in the carried out simulations. Because of this, the required parameters only include the compressive and tensile stresses and the corresponding deformation moduli. These were defined based on experimental tests carried on samples of the component materials. The data of the mechanical characteristics for the materials is summarised in Table 6.

Particular attention was paid to the description of the mechanical response of the steel wires taking into account the periodical bents that are caused by their interweaving. At each crossing between two perpendicular wires, occurring periodically at each mortar joint, these experience a slight bent to allow for their superposition. Therefore, the wires show a slightly ondulated shape that may influence on their final strength and stiffness. This possible influence was analysed by means of experimental tests in tension carried out on ondulated wires embedded in mortar cylindrical specimens. These tests showed that, in spite of the surrounding hardened motar, the ondulated steel wires show mechanical properties significantly lower than those of straight ones of the same type of steel. While the average yield limit for straight wires was of $2,000 \mathrm{~N} / \mathrm{mm}^{2}$, the yield limit of the ondulated wires was of 1,360 $\mathrm{N} / \mathrm{mm}^{2}$. The reduction of the deformation modulus was also significant, as it dropped from 210,000 $\mathrm{N} / \mathrm{mm}^{2}$ for the straight wires to $90,000 \mathrm{~N} / \mathrm{mm}^{2}$ for the ondulated case. In the model, the steel was modelled as equivalent straight bars defined with the overall properties (stress limit, deformation moduli) experimentally determined for the ondulated wires.

The mortar joints, the ceramic units and the elastomeric base are described by means of 20-node solid hexahedral elements, while the steel bars are modelled by means of linear elements. Perfect bond is assumed between the steel bars and the surrounding mortar. A view of the FEM mesh is 
presented in Figure 17.

The elastic base has been calibrated with a hyper elastic $3^{\text {rd }}$ order Yeoh model so as to produce an equivalent coefficient of ballast of $0.06 \mathrm{~N} / \mathrm{mm}^{3}$, in agreement with the one measured experimentally in the static compression test. The corresponding defining parameters are included in Table 6.

Regarding the results, it was observed the specimen showed a linear response in most of the loading process. Only non-linear force vs. displacement responses were observed at the beginning of the simulated loading process. The structural response of each simulated TCT system lad on an elastic base is presented in Figure 18. It might be noted that the numerical model correctly predicts the experimentally measured response for all cases. In addition, it has to be mentioned that the stresses at the mortar, ceramic units and steel remained very low compared with the corresponding stress limits, so the non-linear material definition of the TCT is not necessary for representing the analysed case. However, the non-linear definition of the elastic base is required to represent the initial nonlinear response. Because of this, and to sum up, the required data for the final used optimised model is summarised in Table 6.

Finally, it has to be remarked that the model correctly predicts the lifting of the corners and the stress distribution (see Figure 10, previously mentioned) in the contact between the TCT and the sleeper pad, which has been used to calculate the transmitting area, $A_{1}$, required to calculate the coefficients of ballast.

\section{PROOF OF CONCEPT}

The experimental characterisation of the TCT when used on an elastic base can be used to design pavements and to justify their performance. However, in order to bring evidences of the feasibility of building pavements with the proposed system two prototypes were executed and are herein presented. In addition, the possibility of repairing them is also analysed, and an indirect comparison with classic pavement solution is shown.

First of all, it has to be remarked that the described proof of concept is focused on analysing the installation process and on describing the response when the pavement is loaded with real traffic in a qualitative way. Nevertheless, the two installed TCT solutions were initial proposals, with thicker steel wires, not directly comparable with the experimentally characterised ones. Thus, the results of this 
section have to be carefully analysed as a qualitative approach to assure the feasibility of installing the proposed TCT system as a pavement.

These aims were covered by testing two large pavement samples built so as to represent different conditions regarding the constructive solutions and the substrata. Both pavement samples were subjected to the repeated circulation of two-axle trucks loaded to $60 \mathrm{kN}$ per axle.

The first pavement sample, with an overall surface of approximately $8 \times 19 \mathrm{~m}$, included three regions, of about the same surface, built over different substratum types. In the three cases, the substratum consisted on prepared bed material over a $2 \mathrm{~m}$ deep layer of artificial rubble. In a first region (region A), the bed material consisted of a $15 \mathrm{~cm}$ layer of reinforced concrete built over a $10 \mathrm{~cm}$ layer of gravel. In a second region (region B) the bed material consisted of a $20 \mathrm{~cm}$ layer of well compacted gravel. The third one (region C) included a $20 \mathrm{~cm}$ layer of insufficiently compacted gravel. In all cases, the TCT strips were placed on a layer of sand $2 \mathrm{~cm}$ thick in region $A$ and $4 \mathrm{~cm}$ thick in regions $B$ and $C$. The TCT joints were also filled with sand. A fourth region (region D) involved a conventional unreinforced block pavement, composed of clay blocs, laid over well compacted gravel, a to allow a comparison with the TCT pavement under the same truck traffic.

TCT strips were placed both parallel and transverse to the truck circulation. In addition, two different TCT strip types characterized by a different amount of steel, with steel bars of diameter of $2.5 \mathrm{~mm}$ and $3 \mathrm{~mm}$ respectively, were utilized. The pavement sample was arranged so that every different region would include TCT strips laid in the two directions and also strips with different reinforcement amounts.

The pavement was subjected to the repeated circulation of trucks during several days. Finally, a careful inspection was carried out in order to evaluate the performance of the pavement with focus on the integrity of the sand joints and clay units. It was observed that local soil settlements did only occur, as expected, in the pavement region laid over the insufficiently compacted gravel (region C). In this region, the local settlements caused localized cracking in some of the clay units and some loss of sand in the joints. In the other two regions (regions A and B), no local soil settlements were observed and no sand loss occurred in the joints. However, some cracking was observed in a few units in the TCT strips built over the concrete slab (region A). The clay units of the TCT placed over well compacted gravel (region B) kept fully intact. In region C, the TCT strips placed in the direction parallel to the traffic performed comparatively better (with less mortar loss and unit deterioration) than those 
placed transverse to it.

The conventional unreinforced pavement (region $D$ ) showed larger deformation and damage than the TCT pavement of region $\mathrm{C}$ in spite of being founded on a well compacted gravel substratum. The possibility of an easy repair of the local settlements and damage occurred in region $\mathrm{C}$ was evaluated by actually undertaking a repair consisting of the temporary removal of blocks to allow for the filling of the settled parts below the pavement, and the substitution of damaged blocks. These operations could be carried in an easy and efficient way, thus proving the repairable character of the proposed solution.

A second pavement sample was built using in this case both mortar-filled joints and empty joints. In addition, part of the TCT strips was laid on a slightly sloped substratum in order to evaluate the performance of non-horizontal pavements. The pavement, similarly subjected to truck traffic during several days, performed in a very satisfactory way with no damage observed neither in the clay blocks nor in mortar joints.

\section{DISCUSSION}

The results obtained in the carried out simulations, the real cases application and, particularly, the results of the experimental campaign are herein discussed to deduce practical recommendations of the TCT system working as a pavement.

First of all, regarding the general behaviour of TCT plates it is worth noticing their orthotropic response due to the geometric definition. This behaviour becomes evident by comparing the measurements of the sensors symmetrically placed either in the same row or in the same column. It was observed that the number of joints between the load application point and the measurement point is related with the value of the out-of plane deformation. The measured deflections were larger

when there were fewer joints between the load and the sensor. This effect is even more evident if the joints are mortar-filled. Thus, using more joints (littler pieces) and not casting mortar in them is a way to reduce the deflections transmission along the TCT pavements and reaching the conditions of "classic" tiles pavements.

By analysing the calculated results about the coefficient of ballast (static and cyclic), it is understood that the simplifications made in section 2.3.3 regarding the estimation of a uniform stress applied on 
$A_{1}$ (loaded area of the sleeper pad in the contact with the TCT) might be improved to reduce the scattering. In order to correctly apply the analytical formulation presented in this research, it has become essential knowing the way in which the load is transmitted from the loading tool to the TCT and from the TCT to the elastomeric base, which has been provided by the numerical analysis. However, further experimental research including stress distribution measurement in the interface (TCT-sleeper pad) would be needed to confirm the numerical results.

In the quasi-static tests, the effect of placing sand in the joints does not seem to make a great difference; it just slightly reduces the flexibility of the system. It should be remarked that placing any of the studied TCT types on an elastic base with a coefficient of ballast of $0.0631 \mathrm{~N} / \mathrm{mm}^{3}$ leads to a maximum expected deformation between $2 \mathrm{~mm}$ and $3 \mathrm{~mm}$ under a $6 \mathrm{kN}$ compressive load distributed in a fixed area of $150 \mathrm{~mm} \times 150 \mathrm{~mm}$. Thus, it is demonstrated that the TCT efficiently work as a pavement for pedestrian and light-traffic use whatever the filling of the joints is. The real use of TCT as a pavement (section 5) also supports this statement about the suitability of the system.

Related to the performed cyclic tests, it was observed that the fewer joints there are and the stiffer these joints are, the more proportional response (force-deformation) is registered. However, in all cases a non-linear behaviour during the test was noticed (load decrease) due to viscoelastic effects. The comparison of the cyclic tests on the different specimens showed that the ones with mortar joints transmitted the applied vibration in a more intense way to the rest of the membrane, causing a notable movement at the corners. Among the sand-filled types, only the ones with hollow bricks transmitted the vibration causing the corners to move. This different response might be explained by the greater weight of the solid ceramic tiles and the larger amount of joints in the sample B01_CS which avoided the vibration to be transmitted. The vibration transmission might lead to a loss of the joint filling sand, might cause fatigue damage of mortar joints or might cause the ceramic pieces to penetrate into the soil. All these effects are contrary to the TCT pavement durability. Thus, the use of heavy ceramic pieces, empty or sand-filled joints and little size pieces (to increase the number of joints) are always favourable options. Among all tested samples, P01 is the preferable solution for a TCT pavement subjected to light-traffic.

For the sand-filled joints specimens, a loss of sand was noticed in the joints of the sample B01_CS whereas the sand level remained constant for the test P01_CS. This different behaviour might be 
caused by the holes in hollow pieces that allowed the sand to escape from the joints and into the holes. A constant refilling during the first years after execution may be necessary in the case of pavements built with hollow bricks.

Due to the complexity of the problem, the numerical simulation requires the use of a sophisticated modelling approach involving several materials in combination with contact interface elements. Due to it, using the proposed model configuration for common design purposes becomes difficult. In this case, the use of the apparent coefficient of ballast obtained in this research might be a useful alternative. However, the proposed numerical model can be successfully applied for a detailed study of the mechanical and strength response of the TCT system used as pavement.

\section{CONCLUSIONS}

The studies carried out, involving in situ and laboratory experiments in combination with numerical modelling, have shown the adequate mechanical performance of TCT membranes used for light traffic pavements.

The experimental results obtained on pavement TCT samples, involving different joint types and ceramic pieces, show that it is possible to characterise their mechanical behaviour by experimentally modelling the soil substratum with an elastomeric sleeper pad. In addition, the qualitative comparison between the real application case and the experimental tests indicates that the performed and herein presented laboratory experiments accurately represent the real use conditions.

The tests have allowed the analysis of the influence of each kind of joint type and ceramic unit under static and cyclic loading conditions. In the case of mortar joints, the cyclic movements are strongly transmitted to the rest of the specimen and the free edges experience significant movement. This movement might prevent the application of mortar-filled TCT in the cases with heavy traffic. Sand filled joints seem more suitable due to their larger capacity to dissipate the vibration across the specimen. It must be noted, however, that almost no difference was noticed between the sand filled and the empty joint elements. Solid ceramic pavement units produce large stability thanks to their greater weight which reduces the vibration transmission.

The finite element modelling is regarded as a necessary tool to understand the interaction between the TCT and the elastic base. However, its complexity advises against using it for common design 
purposes. Instead, the analytically calculated coefficients of ballast might be used for practical design activities.

Two different aspects might require further study as suggested by the present experimental results. Firstly, the sand loss in the cyclic loading of samples composed by hollow ceramic bricks should be studied in more detail due to the possible need for refilling them at least during an initial period after the execution of the pavement. Secondly, it seems necessary to improve the experimental method to determine the loaded area of the soil (or base) under each type of TCT membrane $\left(A_{1}\right)$. The observed high influence of this parameter on the analytical formulation developed suggest that it may be necessary to develop an improved experimental method allowing an accurate determination of the contact area between the TCT membrane and the elastic support..

Nevertheless, it is worth remarking that none of the tested samples failed or reached a damaged state during the tests. This indicates that TCT pavements are mechanically suitable for pedestrian and lightweight traffic areas. This, together with their fast execution, provides the TCT pavement system with a competitive performance compared to traditional permeable pavement options.

\section{ACKNOWLEDGEMENTS}

The authors wish to acknowledge Mr. Christian Escrig for providing essential support in the experimental campaign.

\section{REFERENCES}

[1] V. Sarrablo-Moreno, Flexible sheet of bricks for construction of architectural elements, and method for manufacture of said sheet, US 2011/0047914, 2011.

[2] P. Roca, F. Lopezalmansa, J. Miquel, a Hanganu, Limit analysis of reinforced masonry vaults, Eng. Struct. 29 (2007) 431-439.

[3] F. López-Almansa, V. Sarrablo, P.B. Lourenço, J. Barros, P. Roca, F. da Porto, et al., Reinforced brick masonry light vaults: Semi-prefabrication, construction, testing and numerical modeling, Constr. Build. Mater. 24 (2010) 1799-1814. 
[4] F. da Porto, F. Mosele, C. Modena, Experimental testing of tall reinforced masonry walls under out-ofplane actions, Constr. Build. Mater. 24 (2010) 2559-2571.

[5] C. Mayrhofer, Reinforced masonry walls under blast loading, Int. J. Mech. Sci. 44 (2002) 1067-1080.

[6] Y. Chen, a. F. Ashour, S.W. Garrity, Moment/thrust interaction diagrams for reinforced masonry sections, Constr. Build. Mater. 22 (2008) 763-770.

[7] R. Cerioni, G. Donida, A finite element model for the nonlinear analysis of reinforced and prestressed masonry walls, Comput. \&amp; Struct. 53 (1994) 1291-1306.

[8] M. Dhanasekar, W. Haider, Explicit finite element analysis of lightly reinforced masonry shear walls, Comput. \&amp; Struct. 86 (2008) 15-26.

[9] E. Bernat-Maso, L. Gil, P. Roca, V. Sarrablo, C. Escrig, Structural characterisation of textile ceramic technology used as a curtain wall, Eng. Struct. 57 (2013) 277-288.

[10] R.M. Mulungye, P.M.O. Owende, K. Mellon, Finite element modelling of flexible pavements on soft soil subgrades, Mater. Des. 28 (2007) 739-756.

[11] M.N.S. Hadi, B.C. Bodhinayake, Non-linear finite element analysis of flexible pavements, Adv. Eng. Softw. 34 (2003) 657-662.

[12] C. Andersen, I. Foster, The role of urban surfaces (permeable pavements) in regulating drainage and evaporation: development of a laboratory simulation experiment, Hydrol. Process. 609 (1999) 597-609.

[13] M. Nishigaki, Producing permeable blocks and pavement bricks from molten slag, Waste Manag. 20 (2000) 185-192.

[14] M. Scholz, P. Grabowiecki, Review of permeable pavement systems, Build. Environ. 42 (2007) 38303836.

[15] S.-N. Yu, B.-G. Ryu, S.-J. Lim, C.-J. Kim, M.-K. Kang, C.-S. Han, Feasibility verification of brick-laying robot using manipulation trajectory and the laying pattern optimization, Autom. Constr. 18 (2009) 644-655. 


\section{Tables}

Table 1. Characteristics of the tested TCT plates.

Table 2. Mechanic characteristics of the components of the tested TCT plates. Standard deviation in brackets

Table 3. Loading area on the elastomeric base for each TCT plate type and calculated static and cyclic coefficients of ballast of the TCT

Table 4. Experimental results of quasi static tests. Standard deviation in brackets

Table 5. Experimental results of cyclic tests

Table 6. Mechanical characteristics of the materials considered in the simulations 


\begin{tabular}{|c|c|c|c|c|c|c|}
\hline $\begin{array}{c}\text { Sample } \\
(*)\end{array}$ & $\begin{array}{l}\text { Length, } L \\
\text { (mm) }\end{array}$ & $\begin{array}{c}\text { Width, w } \\
\text { (mm) }\end{array}$ & $\begin{array}{c}\text { Row joints thick- } \\
\text { ness, } t_{r}(\mathrm{~mm})\end{array}$ & $\begin{array}{c}\text { Column joints thick- } \\
\text { ness, } t_{c}(\mathrm{~mm})\end{array}$ & $\begin{array}{c}\operatorname{Mass}\left({ }^{* *}\right) \\
(\mathrm{kg})\end{array}$ & $\begin{array}{l}\text { Tests } \\
(* * *)\end{array}$ \\
\hline$B M 1$ & 938 & 977 & 10.7 & 9.5 & 79.05 & $\mathrm{SM} / \mathrm{CM}$ \\
\hline$B M 2$ & 937 & 978 & 10.6 & 10.2 & 73.90 & $\mathrm{CM}$ \\
\hline$B 01$ & 934 & 977 & 9.2 & 9.8 & 59.20 & $\begin{array}{l}\text { SS / SE / } \\
\text { CS / CE }\end{array}$ \\
\hline$P M 1$ & 943 & 1017 & 6.7 & 6.5 & 103.10 & $\mathrm{SM} / \mathrm{CM}$ \\
\hline PM2 & 944 & 1018 & 7.3 & 8.1 & 104.20 & $\mathrm{CM}$ \\
\hline$P 01$ & 940 & 1014 & 8.0 & 6.0 & 96.75 & SS / CS \\
\hline
\end{tabular}

$\left({ }^{*}\right)$ Sample code: Ceramic piece (B: Hollow Brick, P: Solid pavement piece) + Joint material (M: Mortar, 0: Empty or sand filled) + Sample repetition number

$(* *)$ For the specimens with sand filling joints the mass of this sand has not been taken into account.

$(* * *)$ Tests code: SM: Static with the joint filled with Mortar, SS: Static with the joint filled with Sand, SE: Static with the joint Empty, CM: Cyclic with the joint filled with Mortar, CS: Cyclic with the joint filled with Sand, CE: Cyclic with the joint Empty.

Table 1. Characteristics of the tested TCT plates.

Flexural strength (MPa) Compressive strength (MPa) Yield tensile strength (MPa)

\begin{tabular}{lccc}
\hline Mortar joint & $5.32(1.18)$ & $14.4(2.1)$ & -- \\
\hline Hollow brick & $3.32(0.58)$ & $63.5(3.3)$ & -- \\
\hline Solid brick & $6.70(1.59)$ & $71.4(8.1)$ & -- \\
\hline Steel wire & --- & -- & $1360(20)$
\end{tabular}

Table 2. Mechanic characteristics of the components of the tested TCT plates. Standard deviation in brackets 


\begin{tabular}{cccc}
\hline Sample type & $\boldsymbol{A}_{\mathbf{1}}\left(\mathrm{mm}^{2}\right)$ & Static $K_{0}\left(\mathrm{~N} / \mathrm{mm}^{3}\right)$ & Dynamic $K_{\text {dyn_o }}\left(\mathrm{N} / \mathrm{mm}^{3}\right)$ \\
\hline$B M$ & 96211.3 & 0.375 & 1.031 \\
\hline$B O$ & 82957.7 & 0.212 & 0.876 \\
\hline$P M$ & 110446.6 & 0.245 & 0.741 \\
\hline$P O$ & 70685.8 & 0.285 & 0.791
\end{tabular}

Table 3. Loading area on the elastomeric base for each TCT plate type and calculated static and cyclic coefficients of ballast of the TCT

Out-of-plane displacement at the $6 \mathrm{kN} 1$ minute constant load application $\delta(\mathrm{mm})$

\begin{tabular}{cccc}
\hline Test & Beginning $(\mathrm{mm})$ & Ending $(\mathrm{mm})$ & Difference (\%) \\
\hline BM1_SM & $1.70(0.51)$ & $1.77(0.64)$ & 4.1 \\
\hline B01_SE & $2.48(0.79)$ & $2.52(0.79)$ & 1.6 \\
\hline B01_SS & $2.34(1.05)$ & $2.37(1.05)$ & 1.3 \\
\hline PM1_SM & $1.95(0.20)$ & $1.98(0.13)$ & 1.5 \\
\hline P01_SS & $2.28(0.03)$ & $2.32(0.03)$ & 1.8 \\
\hline Elastic base & $4.45(0.11)$ & $4.53(0.10)$ & 1.8 \\
\hline
\end{tabular}

Table 4. Experimental results of quasi static tests. Standard deviation in brackets

Range of load in a cycle ( $\mathrm{kN})$

\begin{tabular}{c|cc|cc|c}
\hline Test & $\begin{array}{c}\text { First cycle } \\
(\mathrm{kN})\end{array}$ & $\begin{array}{c}\text { Reference oscillation } \\
\text { point }(\mathrm{kN})\end{array}$ & $\begin{array}{c}\text { Last cycle } \\
(\mathrm{kN})\end{array}$ & $\begin{array}{c}\text { Reference oscillation point } \\
(\mathrm{kN})\end{array}$ & $\begin{array}{c}\text { Load loss } \\
\%\end{array}$ \\
\hline BM1_CM & $1.80-4.68$ & 3.24 & $1.53-4.47$ & 3.00 & 7.4 \\
\hline BM2_CM & $2.19-5.39$ & 3.79 & $1.93-5.10$ & 3.51 & 7.4 \\
\hline B01_CE & $1.96-4.96$ & 3.46 & $1.72-4.68$ & 3.20 & 7.5 \\
\hline B01_CS & $2.04-5.13$ & 3.59 & $1.81-4.83$ & 3.32 & 7.5 \\
\hline PM1_CM & $1.69-5.50$ & 3.59 & $1.39-5.17$ & 3.28 & 8.6 \\
\hline PM2_CM & $2.13-5.11$ & 3.55 & $1.94-4.89$ & 3.36 & 5.4 \\
\hline P01_CS & $2.03-5.11$ & 3.57 & $1.80-4.83$ & 3.32 & 7.0 \\
\hline Elastic basis & $2.15-5.23$ & 3.69 & $1.96-4.95$ & 3.45 & 6.5 \\
\hline
\end{tabular}

Table 5. Experimental results of cyclic tests 


\begin{tabular}{cccc} 
& Flexural strength (MPa) & Compressive strength (MPa) & Elastic moduli (MPa) \\
\hline Mortar joint & 5.32 & 14.4 & 350 \\
\hline Hollow brick & 3.32 & 63.5 & 12800 \\
\hline Solid brick & 6.70 & 71.4 & 10500 \\
\hline & Yield tensile strength (MPa) & Elastic moduli (MPa) & \\
\hline Steel wires & 1360 & 90000 & Yeoh Constant C30 (Pa) \\
\hline & Yeoh Constant C10 (Pa) & Yeoh Constant C20 (Pa) & -10570 \\
\hline Base & 60950 & 148780 & \\
\hline
\end{tabular}




\section{Figures}

Figure 1. Rolled presentation of TCT by www.flexbrick.es

Figure 2. TCT applied as a structural material for vault production by www.flexbrick.es

Figure 3. Force-displacement response of the elastomeric basis. Quasi-static test. $d$ viscoelastic deformation.

Figure 4. Force-displacement response of the elastomeric basis. Cyclic test. Detail of the first and last loading-unloading cycle from a total of 1000 cycles at $2 \mathrm{~Hz}$

Figure 5. Specimens B01 (left) and PM1 (right) placed in test position

Figure 6. External sensor positions and loading area for tests on TCT plates with hollow bricks (left) and solid pavement ceramic pieces (right). Circular symbol corresponds to potentiometre position and star symbol with laser sensor.

Figure 7. Sketch of the TCT system [1]

Figure 8. Loading procedures for static and cyclic tests

Figure 9. Stress distribution and deformations in the system compound by the elastomeric base (sleeper pad) and a TCT plate

Figure 10. Elastomeric base loading areas $\left(A_{1}\right)$ depending on the type of TCT plate. From left to right, BM, BO, PM, PO samples.

Figure 11. Static test response for TCT sample with hollow bricks

Figure 12. Static test response for TCT sample with solid pavement ceramic pieces

Figure 13. Cyclic behaviour of TCT samples compound by hollow ceramic bricks and mortar joints

Figure 14. Cyclic behaviour of TCT samples compound by hollow ceramic bricks and empty (left) or sand-filled (right) joints

Figure 15. Cyclic behaviour of TCT samples compound by solid ceramic pavement stones and mortar (up) or sand-filled (down) joints

Figure 16. Joints' sand level decrease in test B01_CS

Figure 17. Mesh of the numerical model used to calculate the response of the TCT for the cases BM and PM

Figure 18. Comparison between the experimental response of the TCT and the predicted response by the numerical model 


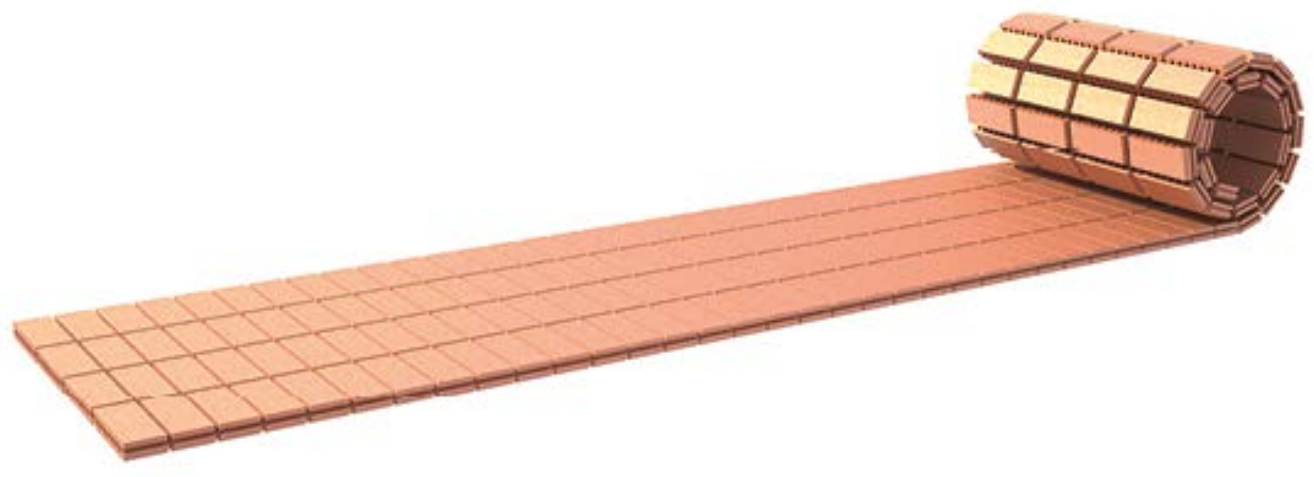

Figure 1. Rolled presentation of TCT by www.flexbrick.es

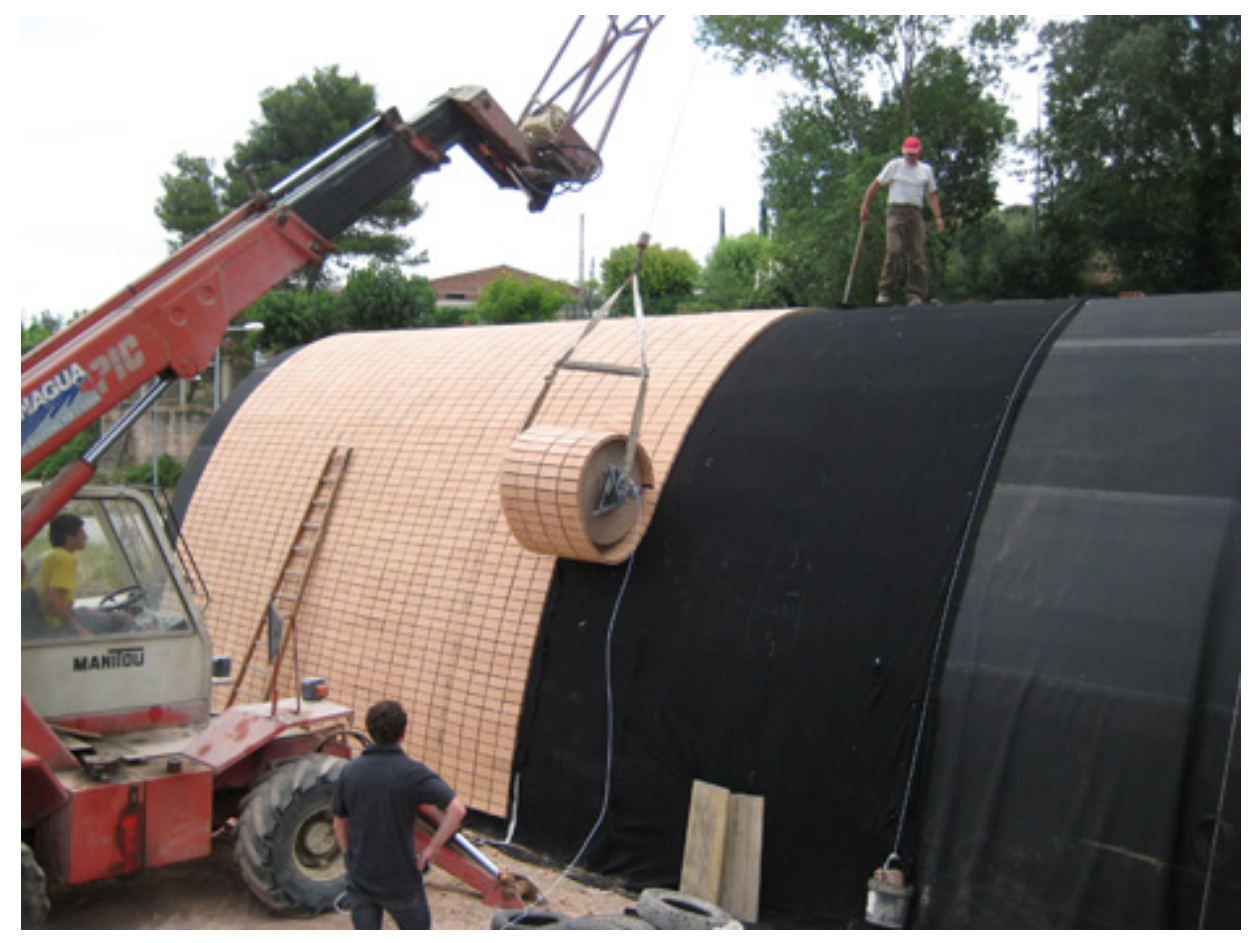

Figure 2. TCT applied as a structural material for vault production by www.flexbrick.es 


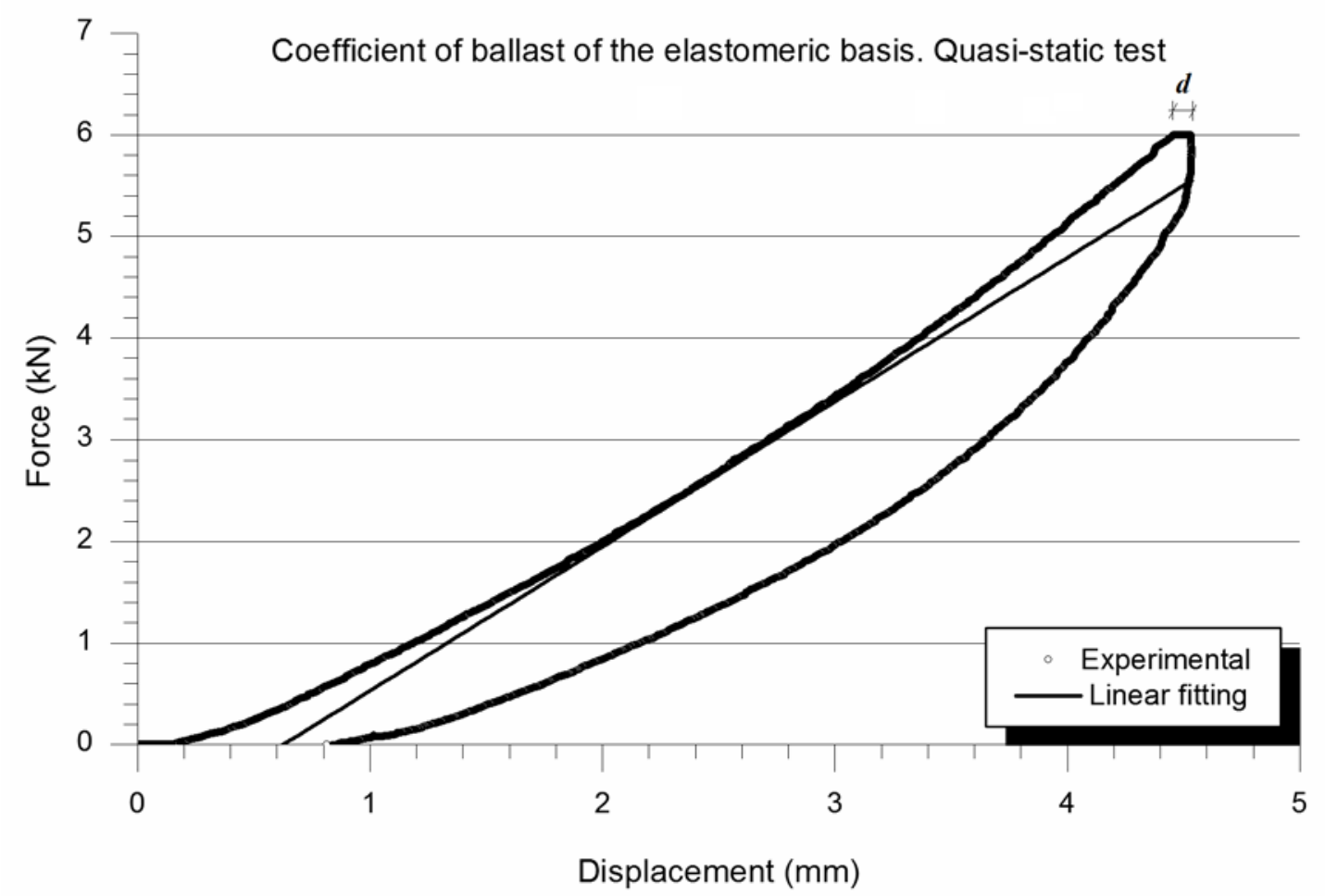

Figure 3. Force-displacement response of the elastomeric basis. Quasi-static test. $d$ viscoelastic deformation.

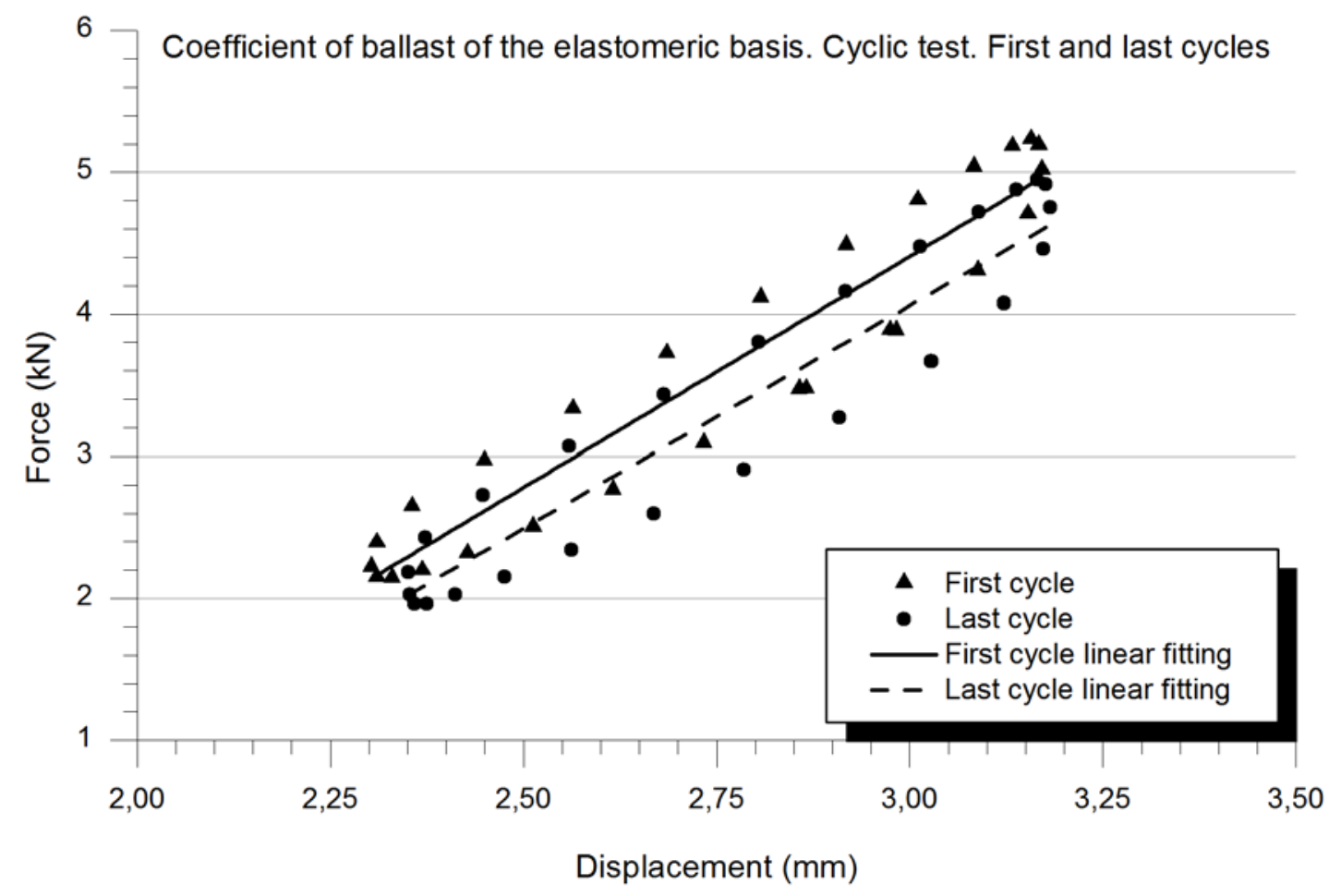

Figure 4. Force-displacement response of the elastomeric basis. Cyclic test. Detail of the first and last loading-unloading cycle from a total of 1000 cycles at $2 \mathrm{~Hz}$ 


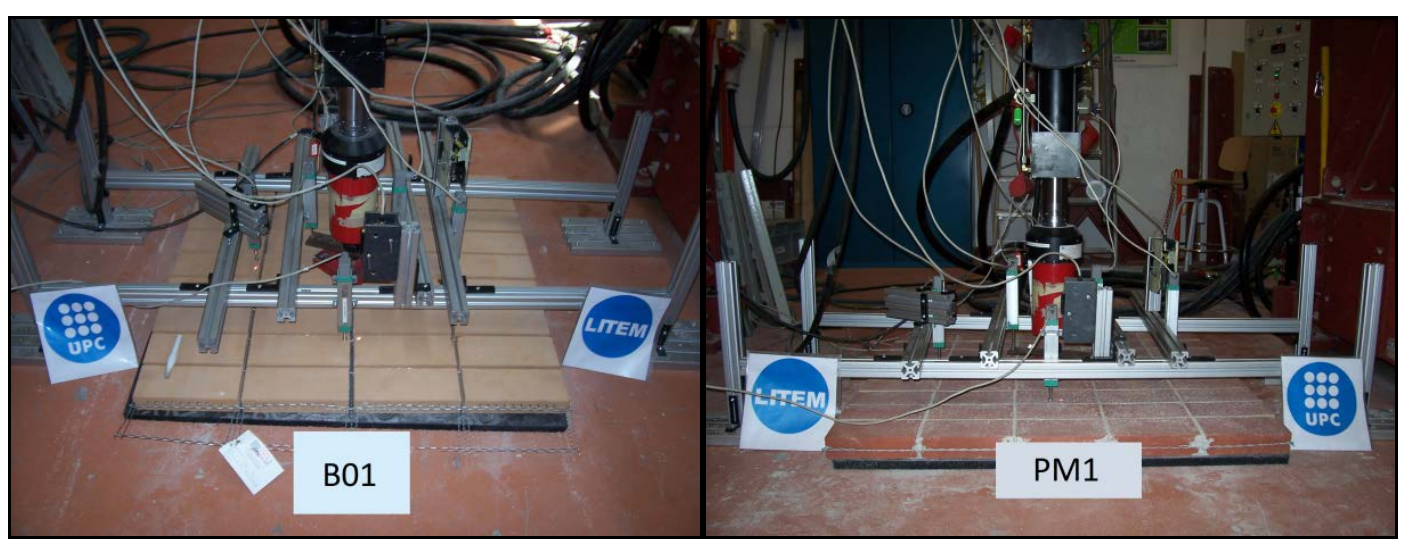

Figure 5. Specimens B01 (left) and PM1 (right) placed in test position
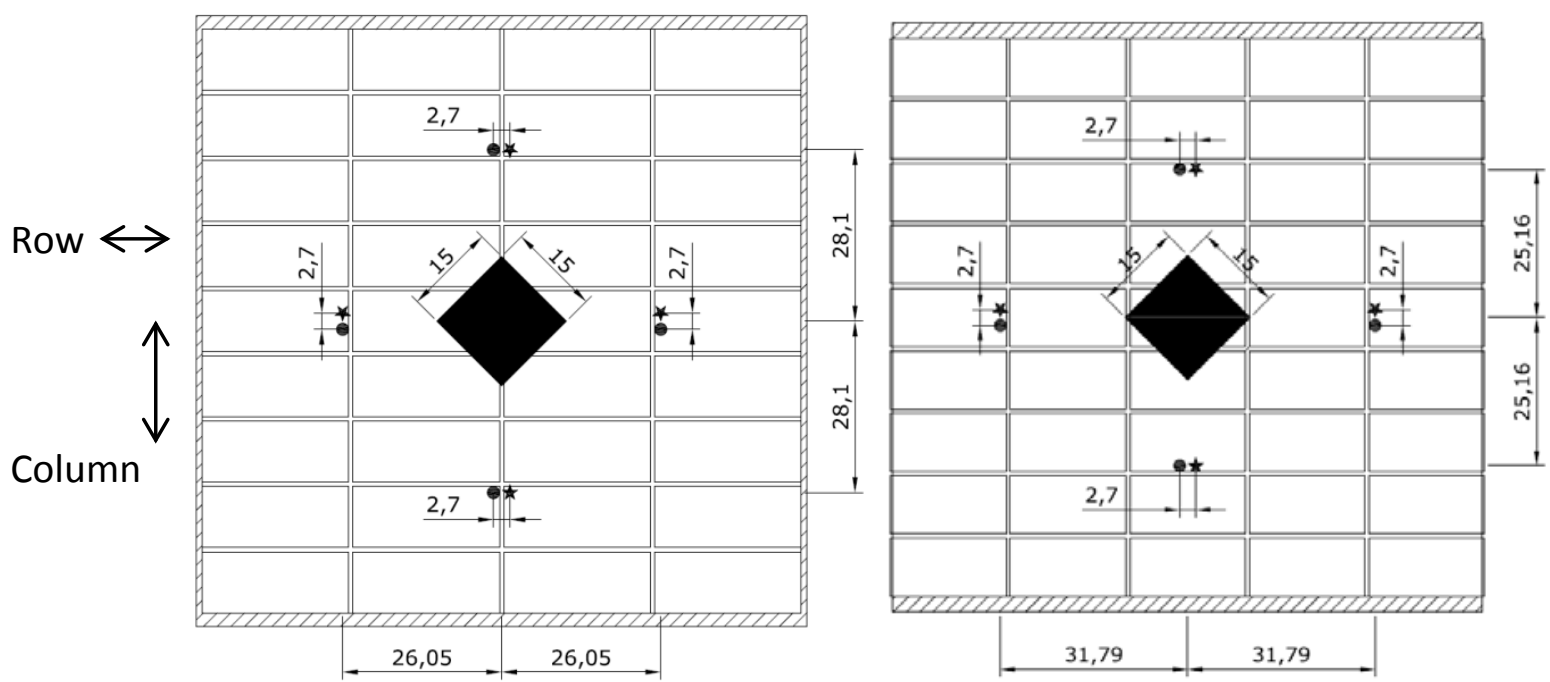

Figure 6. External sensor positions and loading area for tests on TCT plates with hollow bricks (left) and solid pavement ceramic pieces (right). Circular symbol corresponds to potentiometre position and star symbol with laser sensor. 


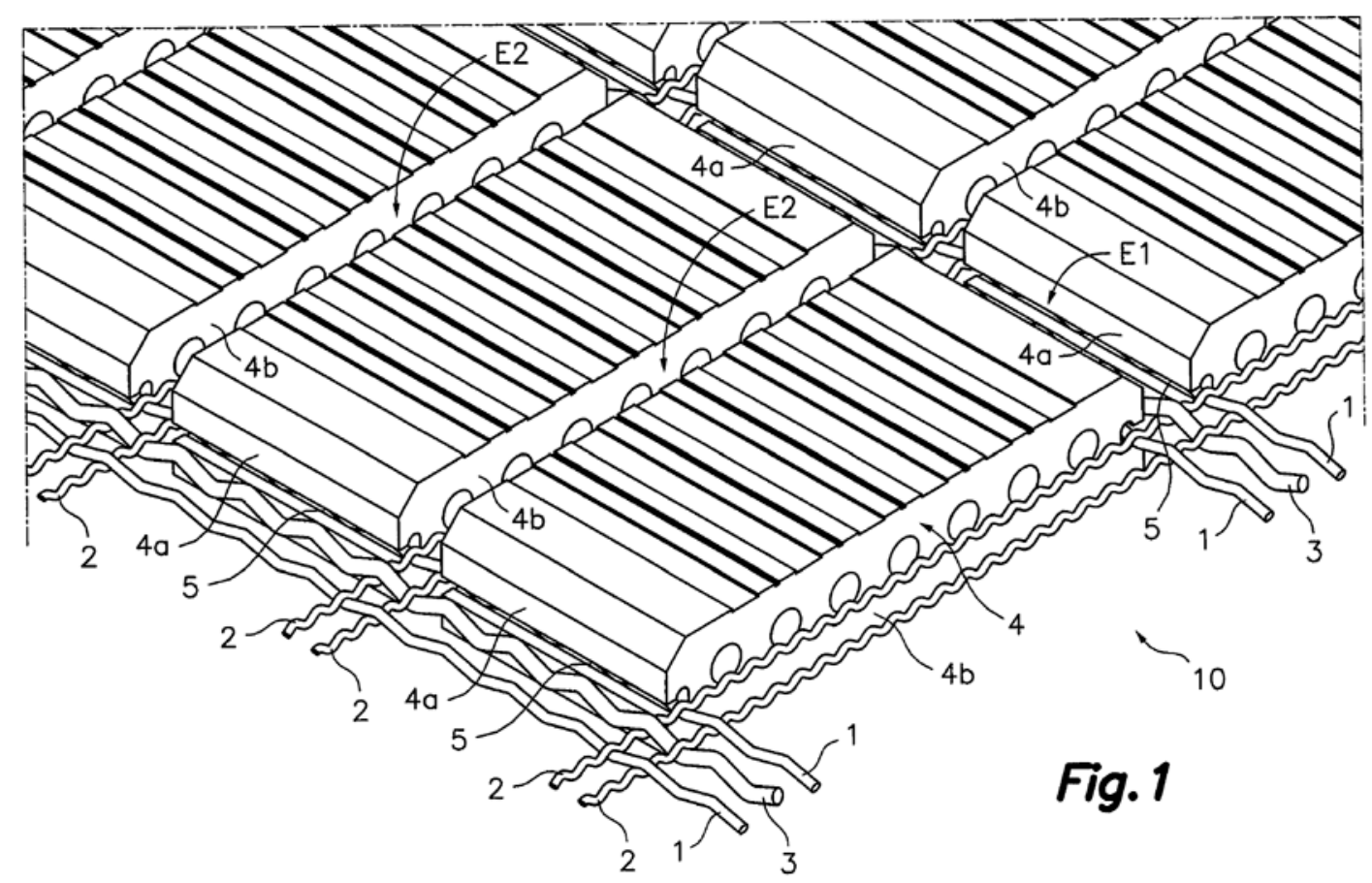

Figure 7. Sketch of the TCT system [1]

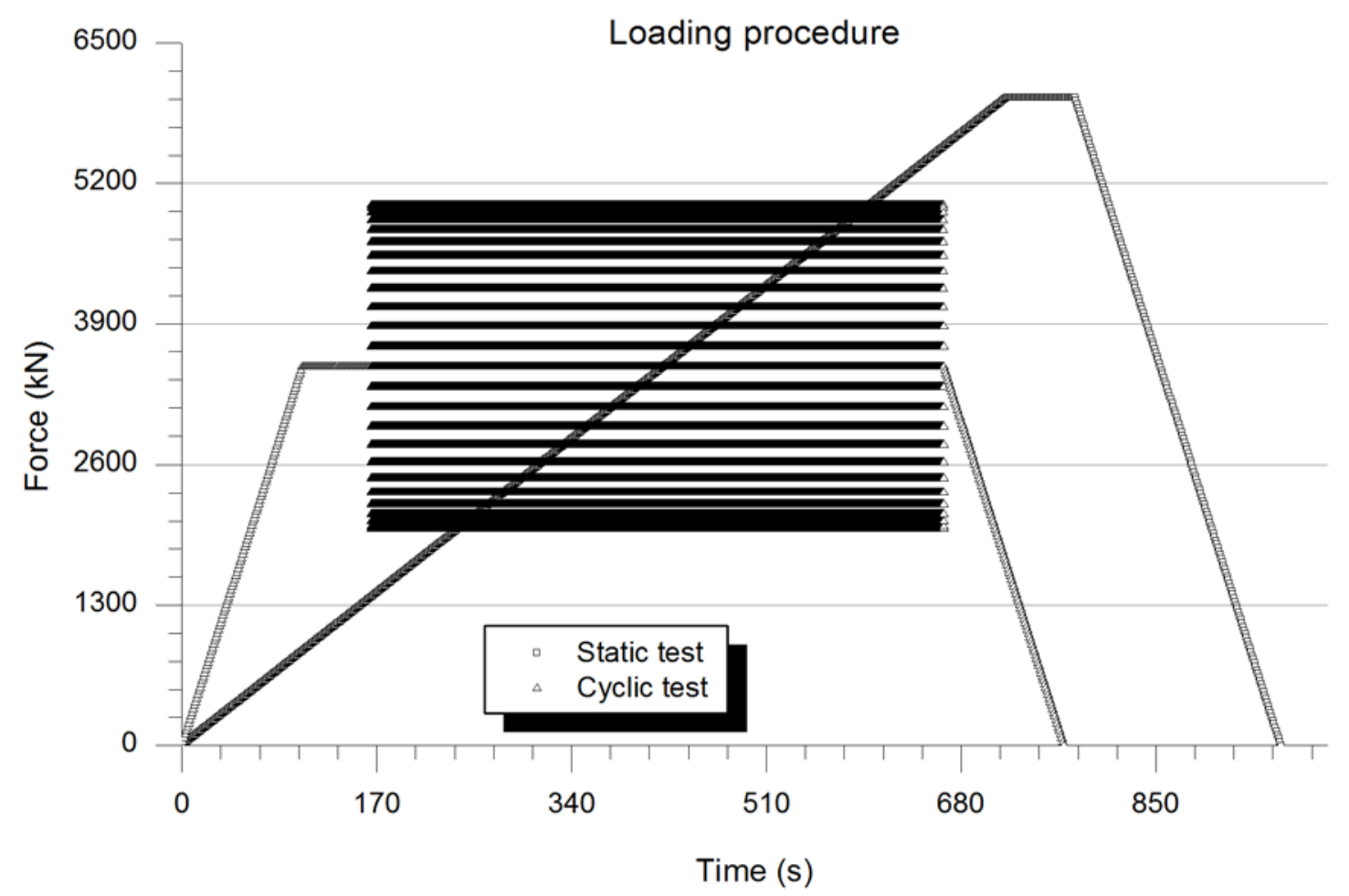

Figure 8. Loading procedures for static and cyclic tests 


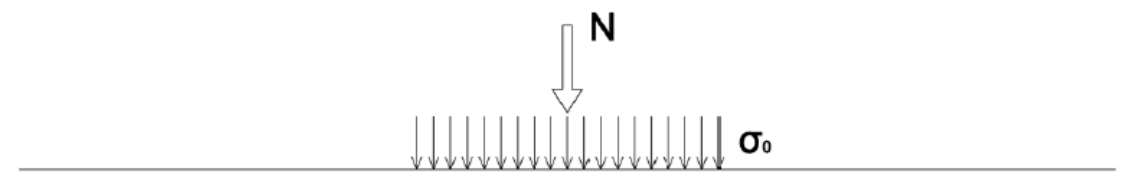

TCT

Sleeper pad

$\downarrow \downarrow \downarrow \downarrow \downarrow \downarrow \downarrow \downarrow \downarrow \downarrow \downarrow \downarrow \downarrow \downarrow \downarrow \downarrow \downarrow \downarrow \downarrow \downarrow \downarrow \downarrow \downarrow \downarrow \downarrow \downarrow \downarrow \downarrow \downarrow \downarrow \downarrow \downarrow \downarrow \downarrow \downarrow \downarrow \downarrow \downarrow \sigma_{1}$
Figure 9. Stress distribution and deformations in the system compound by the elastomeric base (sleeper pad) and a TCT plate $\downarrow \delta$ $\delta_{0}=\delta-\delta_{1}$ $\downarrow \delta_{1}$
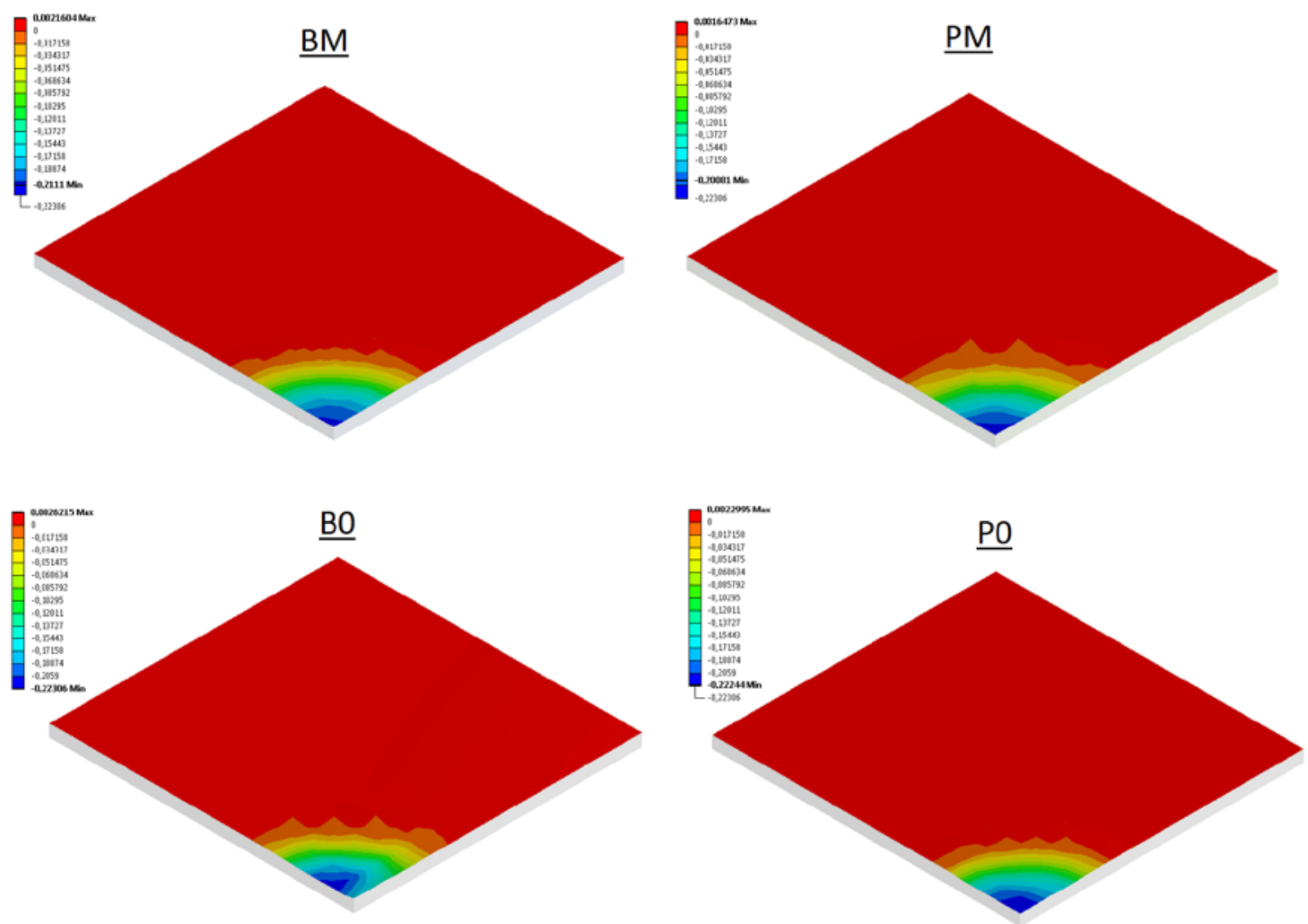

Figure 10. Elastomeric base loading areas $\left(A_{1}\right)$ depending on the type of TCT plate. From left to right, BM, BO, PM, PO samples. 


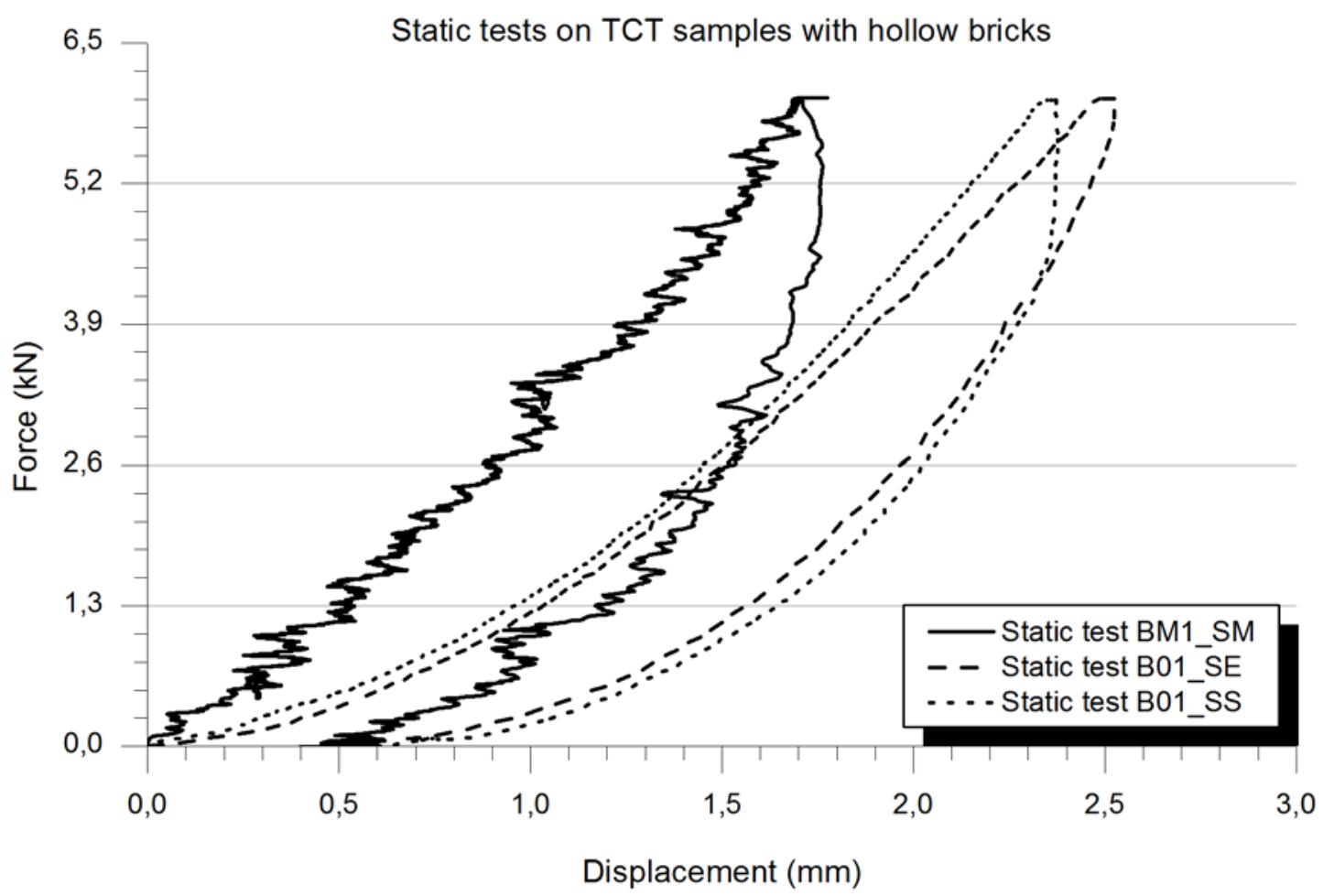

Figure 11. Static test response for TCT sample with hollow bricks

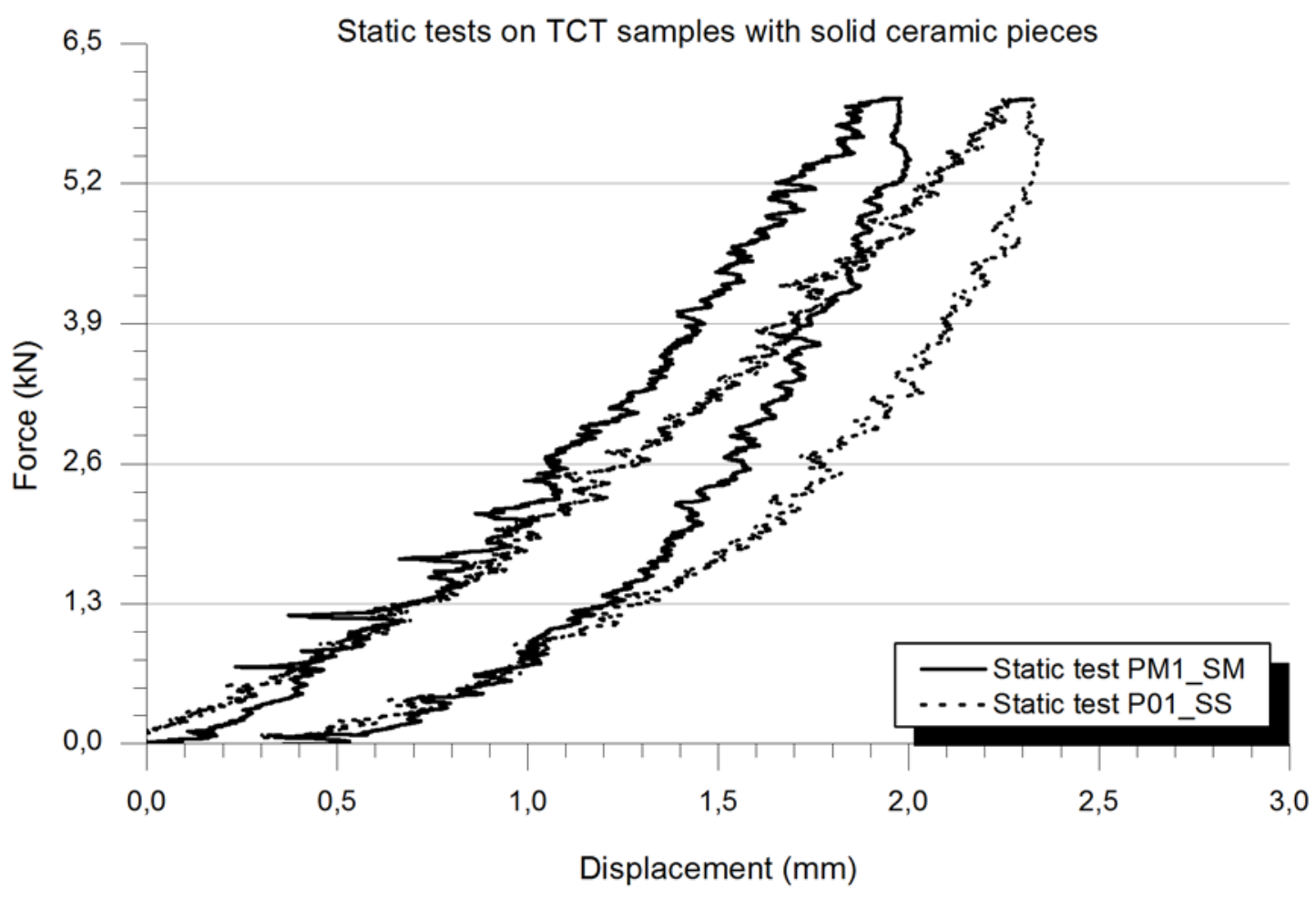

Figure 12. Static test response for TCT sample with solid pavement ceramic pieces 

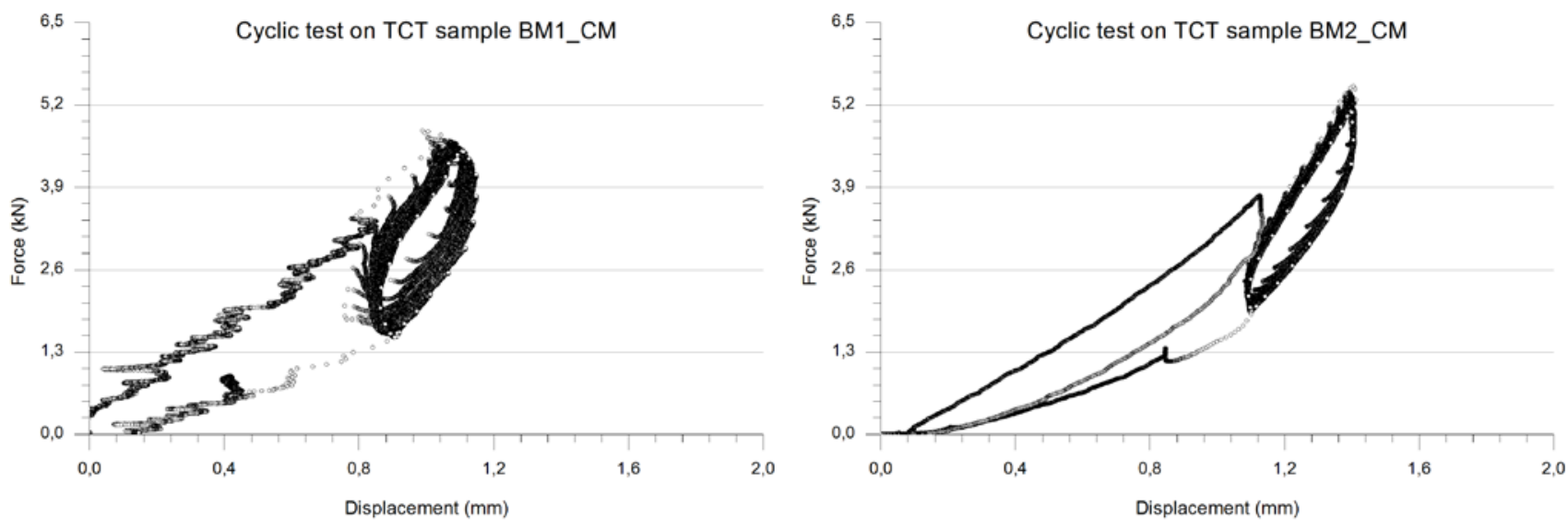

Figure 13. Cyclic behaviour of TCT samples compound by hollow ceramic bricks and mortar joints
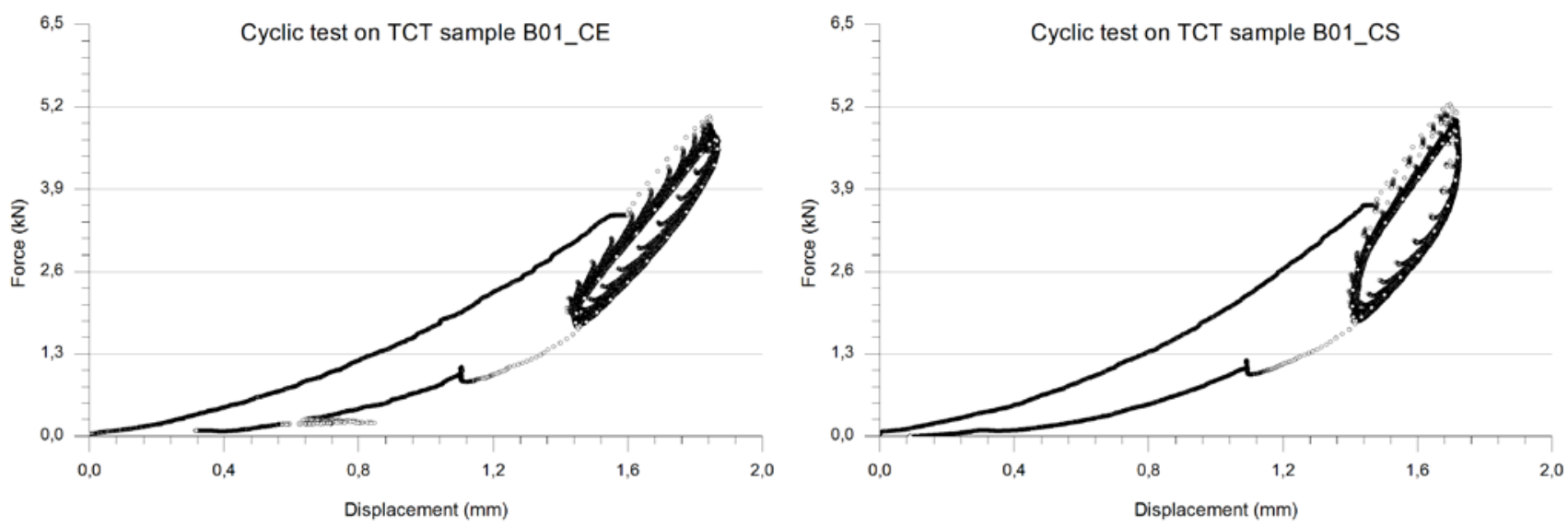

Figure 14. Cyclic behaviour of TCT samples compound by hollow ceramic bricks and empty (left) or sand-filled (right) joints 

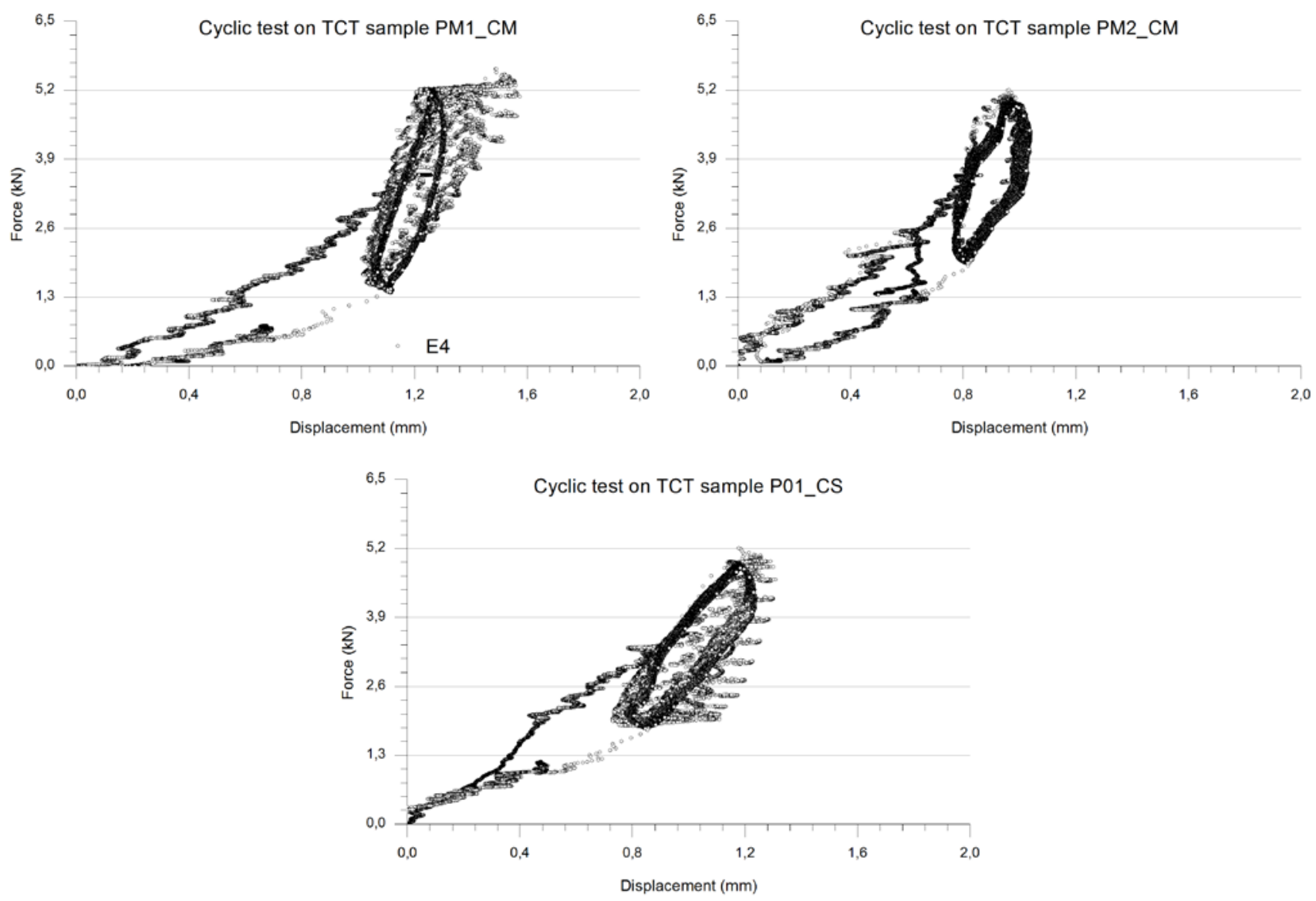

Figure 15. Cyclic behaviour of TCT samples compound by solid ceramic pavement stones and mortar (up) or sand-filled (down) joints 


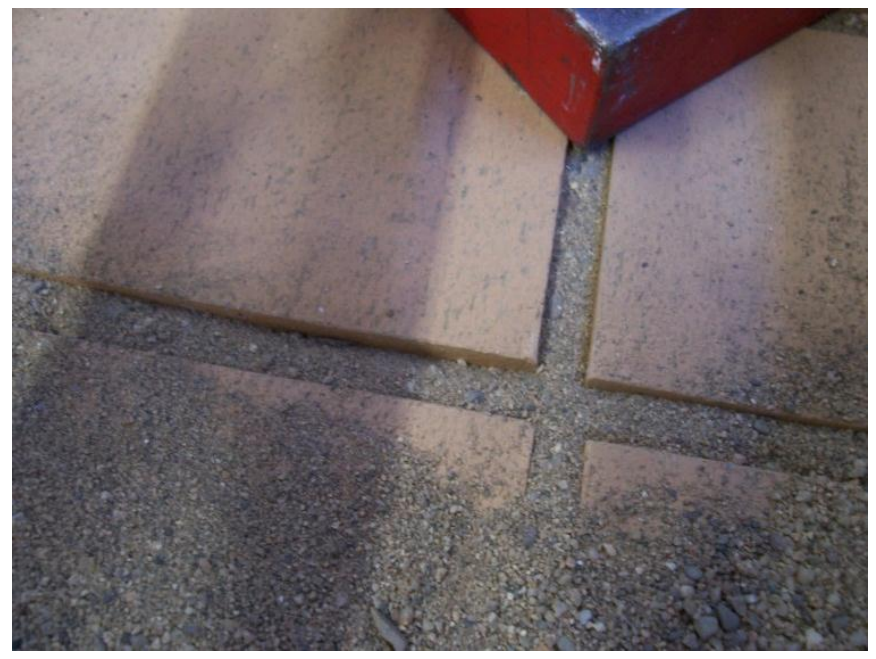

Figure 16. Joints' sand level decrease in test B01_CS
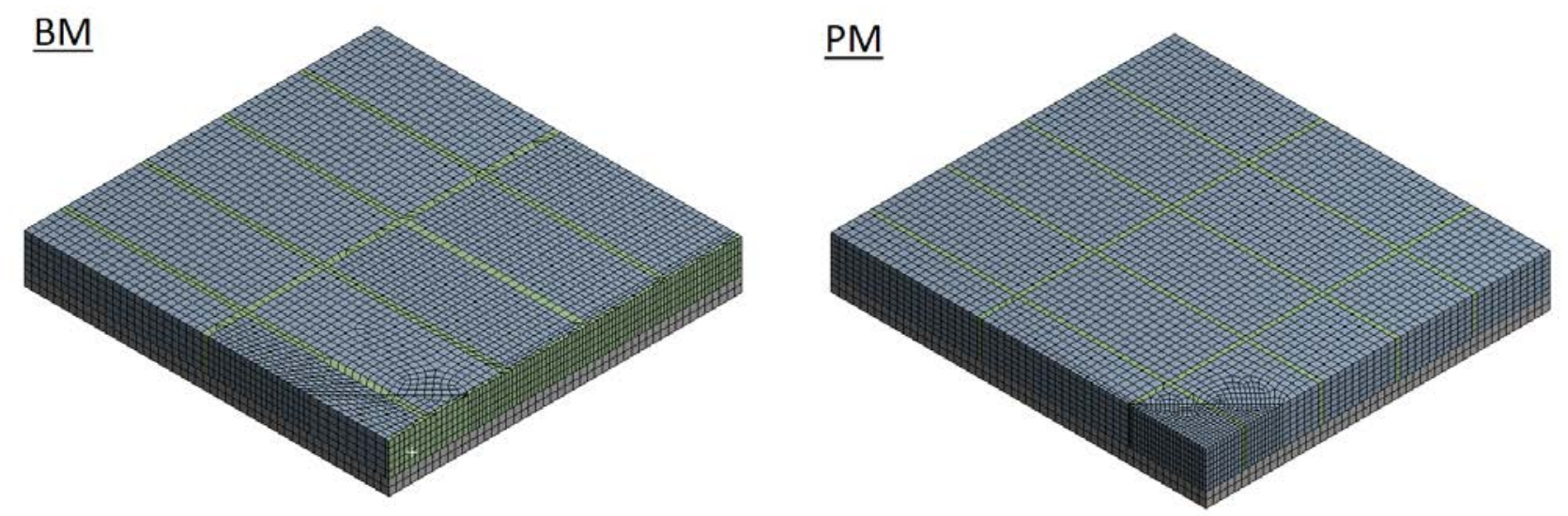

Figure 17. Mesh of the numerical model used to calculate the response of the TCT for the cases BM and PM 

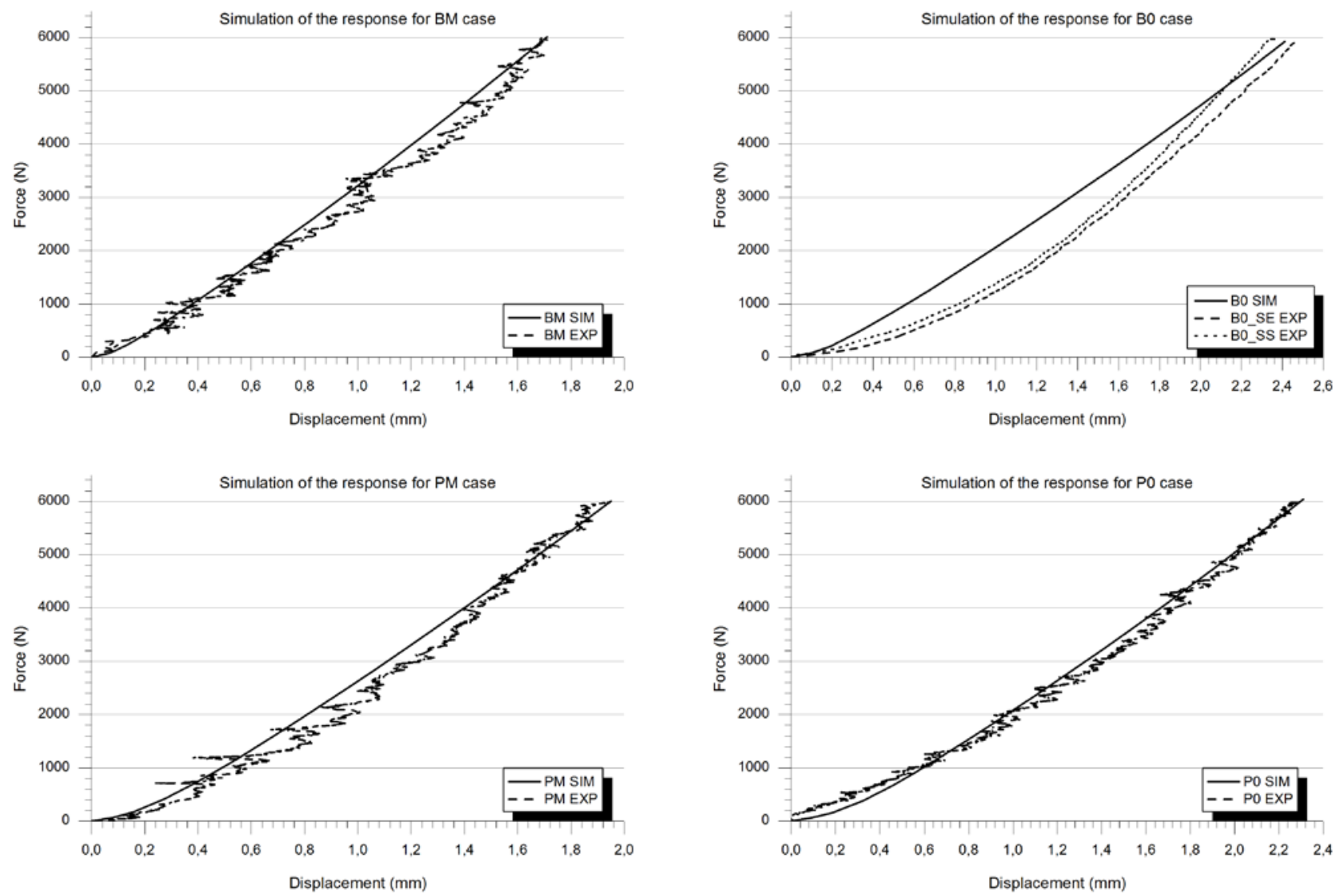

Figure 18. Comparison between the experimental response of the TCT and the predicted response by the numerical model 